\title{
Reservoir Scheduling Using a Multi-Objective Cuckoo Search Algorithm under Climate Change in Jinsha River, China
}

\author{
Yu Feng ${ }^{1,2,3}$, Jijun Xu ${ }^{1,2, *}$, Yang Hong ${ }^{3}$, Yongqiang Wang ${ }^{1,2}$, Zhe Yuan ${ }^{1,2}$ and Chao Wang ${ }^{4}$ \\ 1 Changjiang Water Resources Commission, Changjiang River Scientific Research Institute, \\ Wuhan 430010, China; ferrychip@foxmail.com (Y.F.); wangyq@mail.crsri.cn (Y.W.); \\ yuanzhe_0116@126.com (Z.Y.) \\ 2 Hubei Provincial Key Laboratory of Basin Water Resources and Ecological Environment, Changjiang River \\ Scientific Research Institute, Wuhan 430010, China \\ 3 School of Earth and Space Sciences, Peking University, Beijing 100871, China; yanghong@ou.edu \\ 4 China Institute of Water Resources and Hydropower Research, Beijing 100038, China; wangchao@iwhr.com \\ * Correspondence: xujj07@163.com; Tel.: +86-027-82926390
}

check for updates

Citation: Feng, Y.; Xu, J.; Hong, Y.; Wang, Y.; Yuan, Z.; Wang, C. Reservoir Scheduling Using a Multi-Objective Cuckoo Search Algorithm under Climate Change in Jinsha River, China. Water 2021, 13, 1803. https:// doi.org/10.3390/w13131803

Academic Editor: Juraj Parajka

Received: 30 May 2021

Accepted: 28 June 2021

Published: 29 June 2021

Publisher's Note: MDPI stays neutral with regard to jurisdictional claims in published maps and institutional affiliations.

Copyright: (c) 2021 by the authors. Licensee MDPI, Basel, Switzerland. This article is an open access article distributed under the terms and conditions of the Creative Commons Attribution (CC BY) license (https:/ / creativecommons.org/licenses/by/ $4.0 /)$.

\begin{abstract}
Changes in rainfall and streamflow due to climate change have an adverse impact on hydropower generation reliability and scheduling of cascade hydropower stations. To estimate the impact of climate change on hydropower, a combination of climate, hydrological, and hydropower scheduling models is needed. Here, we take the Jinsha River as an example to estimate the impact of climate change on total power generation of the cascade hydropower stations and residual load variance of the power grid. These two goals are solved by applying an improved multi-objective cuckoo search algorithm, and a variety of strategies for the optimal dispatch of hydropower stations are adopted to improve the efficiency of the algorithm. Using streamflow prediction results of CMIP5 climate data, in conjunction with the Xinanjiang model, the estimated results for the next 30 years were obtained. The results indicated that the negative correlation between total power generation and residual load variance under the RCP 2.6 scenario was weaker than that under the RCP 8.5. Moreover, the average power generation and the average residual load variance in RCP 2.6 was significantly larger than that in RCP 8.5. Thus, reducing carbon emissions is not only beneficial to ecological sustainability, but also has a positive impact on hydropower generation. Our approaches are also applicable for cascade reservoirs in other river catchments worldwide to estimate impact of climate change on hydropower development.
\end{abstract}

Keywords: long-term hydropower generation scheduling; cascade reservoirs; climate change impacts; Jinsha River; multi-objective optimization

\section{Introduction}

Hydropower is one of the most important renewable, and environmentally sustainable energy resources. It can store energy at low costs, maintains lower operating and maintenance costs, and can operate with great stability [1,2]; thus, when integrated with intermittent energy sources, such as solar and wind, can make a significant contribution to the consistency of the energy grid [3,4]. As shown in the 2019 BP Statistical Review of World Energy, global primary energy consumption has grown rapidly in recent years, with hydroelectric generation increasing by $3.1 \%$; however, carbon emissions grew by $2.0 \%$ in 2018 , the fastest over the previous seven years. The emissions of greenhouse gases from anthropogenic activity are the primary mechanism driving the changing global climate, imposing severe stress on the global ecosystem with potentially immeasurable consequences. Climate change is having a direct effect on meteorological factors such as temperature, rainfall, and evaporation, and indirectly affects other factors such as soil moisture content and runoff, resulting in the spatiotemporal redistribution of water resources [5]. It is projected that annual mean streamflow will increase in the high-latitudes and wet tropical regions, 
decrease in most of the dry tropics, and global hydrological extremes, such as rainstorms, floods, and droughts, will continue to increase significantly, preventing investors from accurately forecasting future energy production $[6,7]$. Variability in streamflow resulting from climate change is likely to have a significant impact on hydropower generation [8]. The impact factors of climate change on river systems, such as temperature fluctuations, rainfall patterns, floods, and droughts $[9,10]$, have a direct or indirect influence on hydropower generation [11]. Accordingly, hydropower planning must be careful and take into account the potential changes in river streamflow as a result of a changing climate [12], and such research is critical for the development of mitigation plans.

Increasing anthropogenic activities over the past century have resulted in increased atmospheric concentrations of greenhouse gases $\mathrm{CO}_{2}, \mathrm{CH}_{4}$, and $\mathrm{N}_{2} \mathrm{O}$, the primary gaseous drivers of climate change [13]. Increases in global temperature are self-accelerating, as the melting snow in polar regions and high-altitude mountains decreases surface albedo as lowelevation snow cover, glaciers, and permafrost are in decline [14]. The melting of glaciers and snow in the polar regions, and the resulting rise in sea level, will increase oceanic area, which along with higher temperatures, will increase evaporation and correlated large-scale changes in the global water cycle. Water vapor from the ocean is converted into precipitation, and when rainfall increases or decreases in wet or dry areas, respectively, the probability of natural disasters, such as floods and droughts, increases significantly. Changes in glacial and snow-covered areas of mountains have also altered river runoff [15]; however, streamflow changes by region have neither consistently increased nor decreased.

With respect to the indirect impacts of climate change on hydropower, higher surface air temperatures will change the temperature and stratification of a reservoir [16], then increase evaporation over the reservoir, reducing the amount of available water [17]. Second, stronger rainfall will bring increased pollutants into rivers, potentially exacerbating reservoir contamination, and the resulting wear and corrosion of turbines by pollutants will reduce power generation efficiency [18]. Third, as reservoirs require constant water supply regulation, rising temperatures will increase agricultural and domestic water demand, reducing reservoir storage levels, resulting in a decrease in the water head and generation flow.

The research here investigated the impacts of climate change on hydropower production and proposed a method to quantitatively analyze the economic effects on power generation of the cascade hydropower stations along the Jinsha River, China. The remainder of this paper is organized as follows: Section 2.1 describes the available methods for quantitative analysis; Section 2.2 presents the improved multi-objective cuckoo search algorithm (MoCS), a tool for finding optimal solutions; Sections 2.3 and 2.4 describes the multi-objective hydropower generation model (MLTHG) and the application of MoCS to deal with its limitations; Section 3 describes the impact of future climate changes on reservoir scheduling in the Jinsha River; and Section 4 provides a summary conclusion.

\section{Methods}

\subsection{Estimating Climate Change Impacts on Hydropower}

New tools, such as the latest generation of general circulation models (GCMs) and downscaling methods, have advanced the ability to study the potential impacts of climate change on hydropower generation [19]. It is possible to identify the impact of climate change on water resource by simulating climate change scenarios [20]. The most common method is to run a calibrated baseline hydrological model under changing hydro-climatic conditions to estimate streamflow [21] and using this value as the input of the power system model [22-24].

Climate change is a complex process characterized by massive uncertainty; accordingly, future research scenarios based on a series of scientific assumptions are generally adopted, using GCMs to simulate the future climate conditions. In combination with downscaling technology, GCM climate data can be converted to that required by hydrological models, such as empirical statistical, conceptual hydrological, and distributed hydrological 
models, and ultimately be used to assess the impact of climate change on water resources. The conceptual hydrological model is a physical approach to describing the relationship between hydrological factors by generalizing complex phenomena $[25,26]$. The distributed hydrological model, such as TOP model, SWAT, Mike SHE, and VIC, divides the watershed into multiple sub-simulation units, and performs separate hydrological simulations to better reflect the characteristics of medium-and large-scale watersheds $[27,28]$.

After completing a rainfall runoff simulation, a power system model can be applied to estimate the impacts on energy production. For example, Queiroz et al. introduced spatiotemporal information of future climate change into the operation plan of Brazil's hydropower system to evaluate its impact on the revenue of hydropower stations [29]. By applying GCM projections, the trend of hydropower demand over the next 30 years can be obtained [30]. Other objectives can also be estimated through this method. For example, Zhai et al. predicted the trend of inflow of the Jinsha river through two climate models and carried out a qualitative analysis of the possible strategies of hydropower stations for flood control purposes in the future [31]. Zhang et al. studied the derivation and the adaption of operating rules for the irrigation reservoir under climate change [32].

To best estimate the impact of climate change on hydropower, a combination of climate, hydrological, and power system models is needed. The accuracy of the hydrological model, and the efficiency of the power system model, will determine the accuracy of the climate change impact prediction. Uncertainty of the results mainly comes from three aspects: Observational Uncertainty, Model Structural Uncertainty, and Parametric Uncertainty. In order to evaluate the uncertainty, probabilistic analysis methods, such as Expectancy Method, Utility Function Method, and Model Analysis, are mainly used. Given the uncertain factors a random change within a certain range, analyze and determine the probability distribution of this change, so as to calculate its expected value and standard deviation. The flowchart of the method used in this paper is shown in Figure 1. Details will be explained in the following sections.

\subsection{Improved Multi-Objective Cuckoo Search Algorithm}

\subsubsection{NGSA-II}

In general, real-world engineering problems must consider multiple goals, and tradeoffs are required for goal optimization; therefore, one must consider the relationship between conflicting targets to obtain the most reasonable multi-objective solution that maximizes total benefits. The concept of "dominance" is commonly used in multi-objective optimization algorithms. Pareto optimal solutions are feasible, and not dominated by other arbitrary solutions in the set. The multidimensional space formed by the target values of all Pareto optimal solutions is the Pareto optimal front; at present, the main methods for obtaining the frontal space are mathematical programming and intelligent algorithms.

Elitist nondominated sorting genetic algorithm $v$. II (NSGA-II) is a popular genetic algorithm-based multi-objective optimization method. It uses an elite strategy and maintains population diversity through the operator of crowding comparison. The basic process of NSGA-II is:

(1) Randomly generate an initial population of size N. Then, sort the initial population using the non-dominated method.

(2) Generate new subpopulations through selection, crossover, and mutation operations of the evolutionary algorithm.

(3) Merge the parent and child populations and select the most fit individuals to form the next-generation population based on a dominance relationship and crowding degree.

(4) Repeat the above processes until the termination condition is met.

\subsubsection{Improved Cuckoo Search}

The cuckoo search (CS) algorithm is a meta-heuristic method developed by Yang and Deb (2009). It is inspired by the obligate brood parasitism of some cuckoo species [33]. 


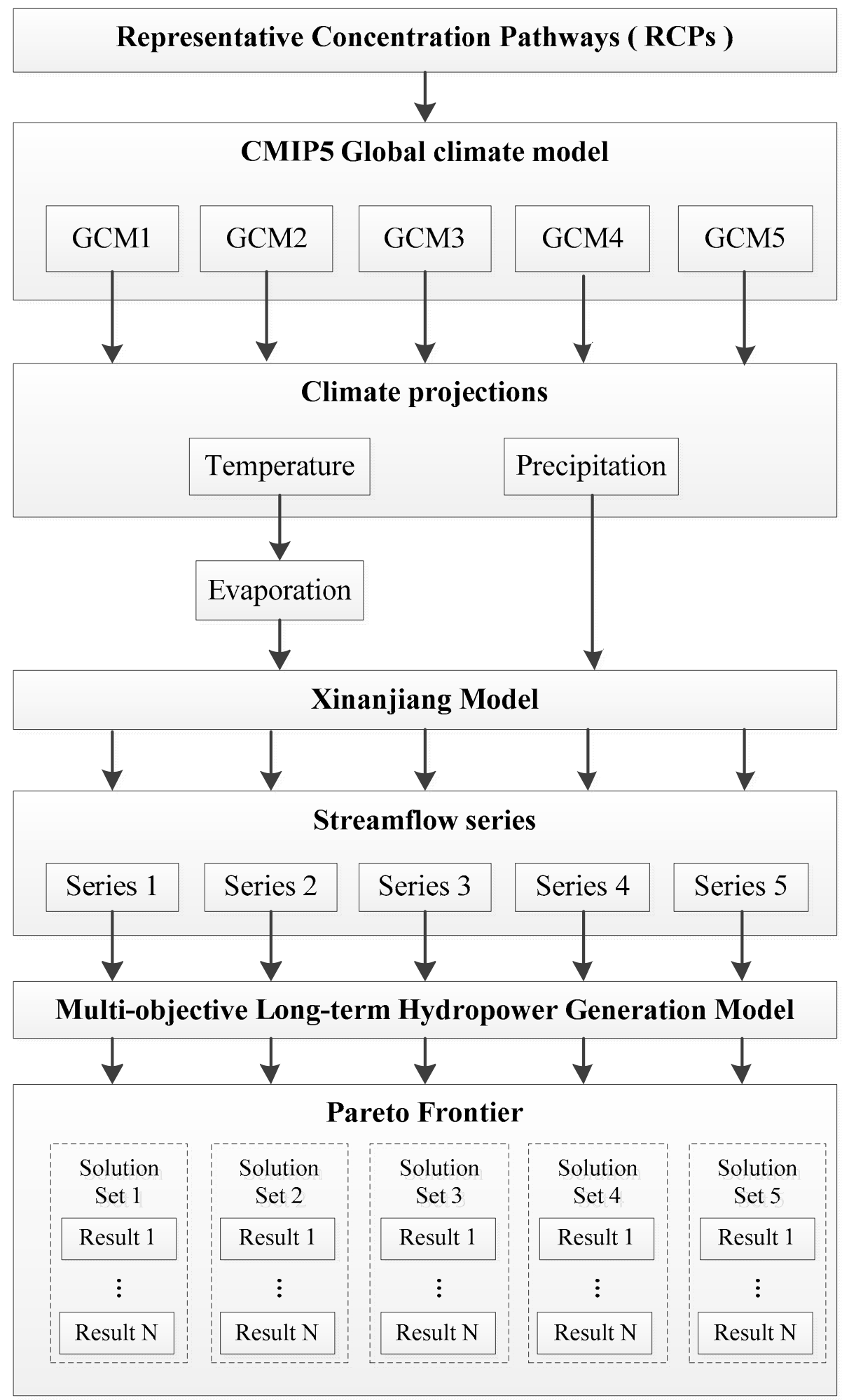

Figure 1. Flowchart for assessing the impact of climate change on hydropower generation.

The most important feature of the CS algorithm is the use of Lévy flight characteristics, where a number of studies have shown that the behavior of many insects and larger animals exhibited the typical characteristics of a Lévy flight, shown by a power-law behavior. Inspired by this action, a new solution was generated as follows:

$$
x_{i}^{t+1}=x_{i}^{t}+\alpha \oplus \operatorname{Levg}(\lambda)
$$


Research has shown that the strength of the local convergence ability of basic CS insufficiently and several improvements have been proposed to improve its performance:

(1) Dynamic parameter adjustment strategy

In the basic CS algorithm, the abandon probability $\left(p_{a}\right)$ is a fixed value that affects the convergence speed of the algorithm. The improved solution turns $p_{a}$ into a dynamic adjustment using Equation (2):

$$
p_{a}=p_{a}^{s}+\left(p_{a}^{e}-p_{a}^{s}\right) \times \frac{C E}{N E}
$$

where $p_{a}^{s}$ and $p_{a}^{e}$ are the start and end of $p_{a}$, respectively, and $C E$ and $N E$ are the current and maximum evaluation times, respectively.

\section{(2) Differential strategy for Lévy flight}

Originally, Lévy flights were described according to Equation (3), although the details of its implementation are not provided. Different interpretations of this formula have been suggested by researchers, and in the present study, we implemented the equation using the differential strategy as follows:

$$
x_{i}^{d \prime}=x_{i}^{d}+\left(s l \times \operatorname{Levy}(u, c) \times\left(x_{j}^{d}-x_{i}^{d}\right)\right)
$$

where $x_{i}$ and $x_{j}$ are randomly chosen nests, $s l$ is the step size, and Lev $y(u, c)$ is the sample value generated by the Lévy distribution. The probability density function of $\operatorname{Levy}(u, c)$ is calculated according to Equation (4):

$$
f(x)=\sqrt{\frac{c}{2 \pi}} \frac{e^{-\frac{c}{2(x-u)}}}{(x-u)^{3 / 2}}
$$

\section{(3) Revised solution}

The basic CS generates a new solution and compares it with randomly chosen ones from the nests. If the randomly chosen solution is inferior, it is replaced; however, the two solutions are irrelevant, and the conversion is inadequate, and the source solution of the new solution should be replaced accordingly. The pseudo-code of the improved cuckoo search (ICS) Algorithm 1 is as follows:

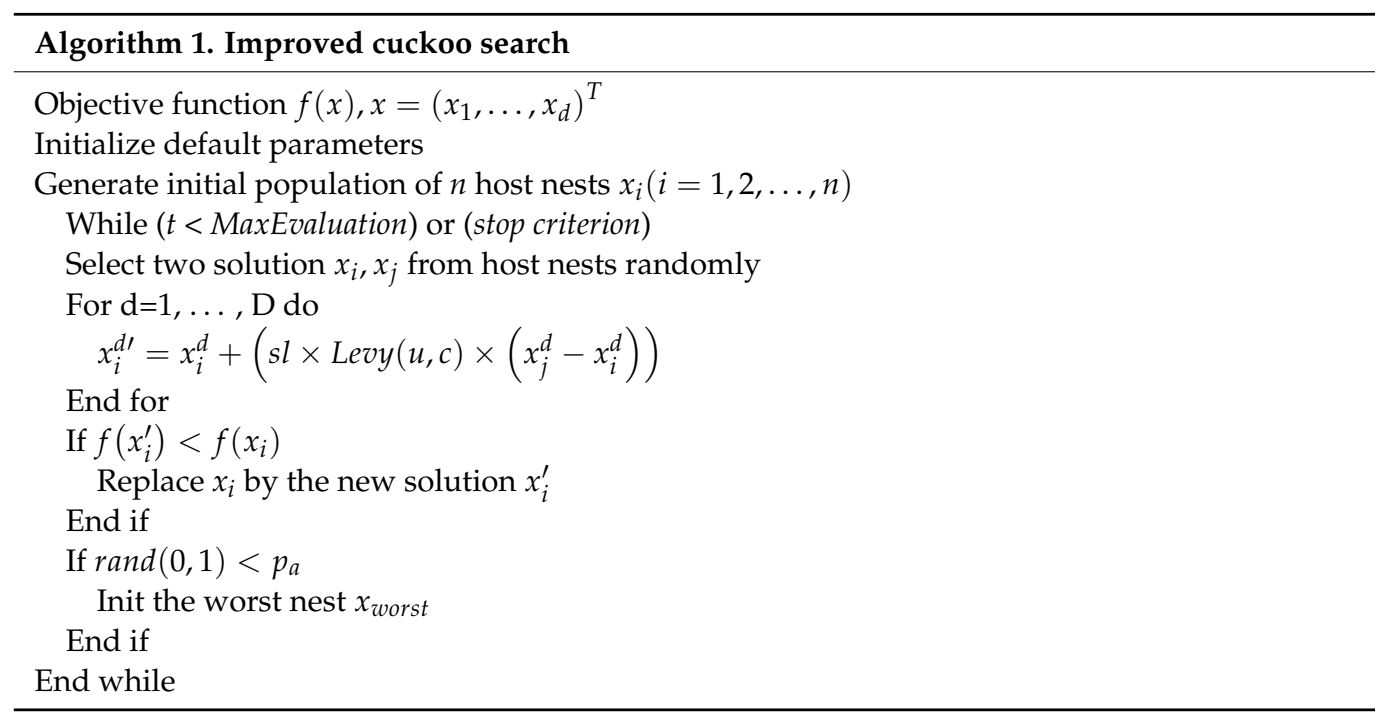




\subsubsection{Multi-Objective Cuckoo Search}

The multi-objective cuckoo search (MoCS) in the present study was based on the NSGA-II algorithm and the improved cuckoo search algorithm described above. The MoCS procedure is explained as follows (Figure 2):

(1) Generate a random initial population, and classify the individuals using the nondominated sorting method. A new population can then be generated using the ICS algorithm.

(2) Merge the parent and child populations, employ a fast, non-dominated sorting and crowding degree calculation in the mixed population, and select the most fit individuals to form the next generation.

(3) Repeat the processes above until the termination conditions are met.

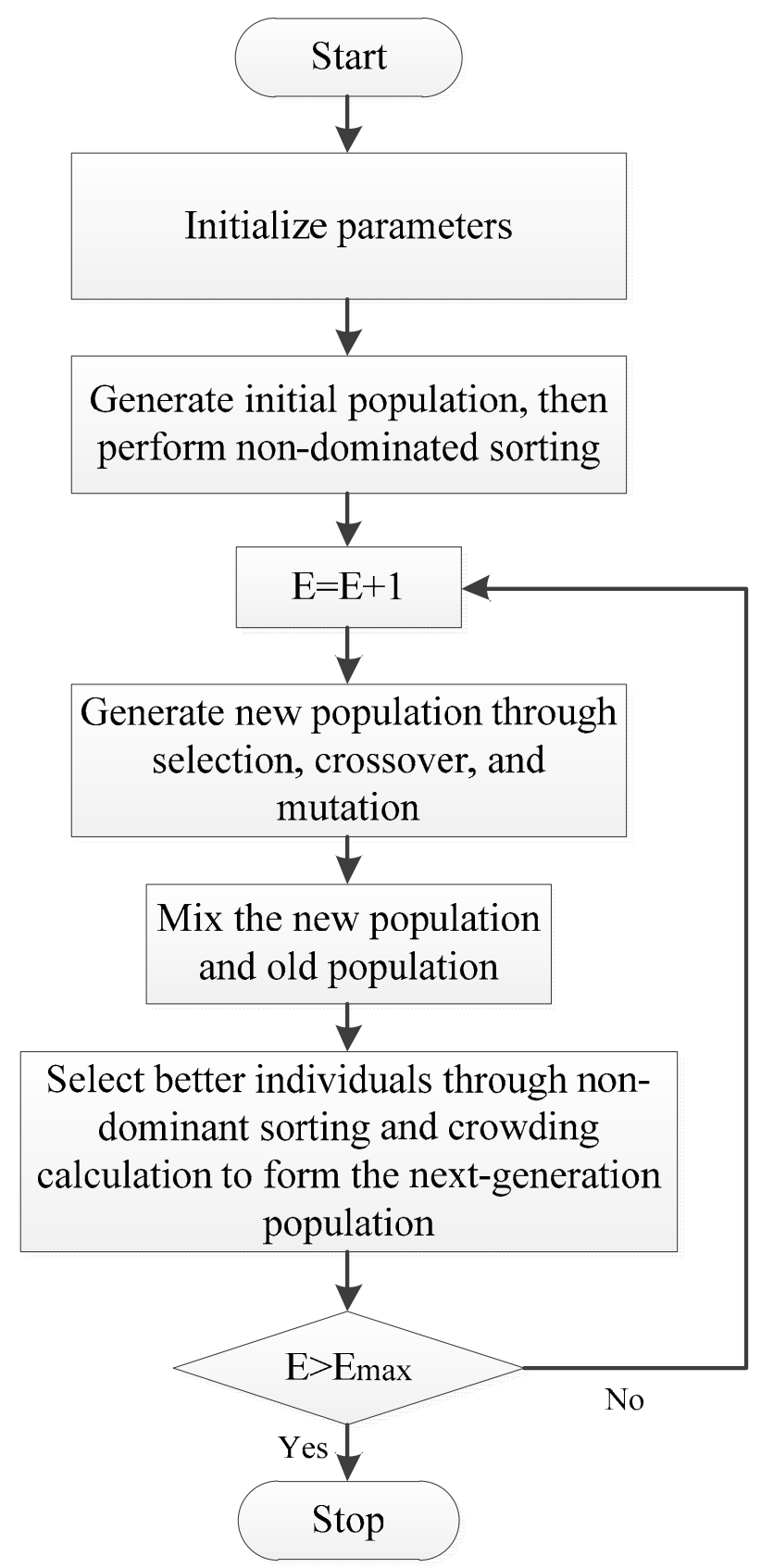

Figure 2. Flowchart of MoCS. 


\subsection{Gradient Multi-Objective Cuckoo Search for Reservoir Scheduling}

A reasonable scheduling plan can achieve efficient trade-offs for various conflicting objectives [34]. The objectives and constraints of the multi-objective long-term hydropower generation (MLTHG) are described in this section, as is the application of the MoCS for MLTHG.

\subsubsection{Power Generation Objective}

One of the optimization goals of the MLTHG is to maximize total power generation of cascade hydropower stations, using the following formula Equation (5):

$$
f_{1}=\max \sum_{t=1}^{T} \sum_{i=1}^{N} k_{i} Q_{i, t} H_{i, t} \Delta t
$$

where $f_{1}(\mathrm{~kW} \cdot \mathrm{h})$ is the total energy production of the cascade hydropower system, $T$ is the period count, $N$ is the number of reservoirs, $k_{i}$ is the output coefficient of reservoir $i, Q_{i, t}$ $\left(\mathrm{m}^{3} / \mathrm{s}\right)$ is the generation of outflow through hydropower units of reservoir $i$ at time $t ; H_{i, t}$ $(\mathrm{m})$ is the net water head of hydropower reservoir $i$ at time $t$, and $\Delta t$ is the length of the time interval.

\subsubsection{Residual Load Variance Objective}

An important function of a hydropower station is to optimally respond to the power grid, thus minimizing the residual load; however, this objective is not easily resolved, and researchers have carried out a variety of targeted improvements towards this end. In the present study, the objective was to minimize the residual load variance of the power grid, according to the following formula Equation (6):

$$
\left\{\begin{array}{c}
f_{2}=\min \left(\sqrt{\sum_{t}^{T}\left(P_{t}-\bar{P}\right)^{2}}\right) \\
P_{t}=\sum_{i=1}^{N} k_{i} Q_{i, t} H_{i, t}
\end{array}\right.
$$

where $f_{2}(\mathrm{~kW})$ is the residual load variance of the power grid, $P_{t}(\mathrm{~kW})$ is the total power output of the cascade hydropower stations over period $t$, and $\bar{P}(\mathrm{~kW})$ is the average power output of all periods. Notably, it is necessary to maintain a low water level during the flood season due to flood control requirements; thus, this season was not considered in the formula.

\subsubsection{Constraints}

(1) Hydraulic connection (Equation (7)):

$$
\left\{\begin{array}{l}
I_{i, t}=O_{i-1, t}+R_{i, t} \\
O_{i-1, t}=Q_{i-1, t}+S_{i-1, t}
\end{array}\right.
$$

where $I_{i, t}\left(\mathrm{~m}^{3} / \mathrm{s}\right)$ is the inflow of reservoir $i$ at time $t ; O_{i-1, t}\left(\mathrm{~m}^{3} / \mathrm{s}\right)$ is the outflow of reservoir $i-1$ at time $t, R_{i, t}\left(\mathrm{~m}^{3} / \mathrm{s}\right)$ is the interval inflow between reservoir $i-1$ and $i ; S_{i-1, t}\left(\mathrm{~m}^{3} / \mathrm{s}\right)$ is the spillage of the upstream reservoir $i-1$, and $Q_{i-1, t}\left(\mathrm{~m}^{3} / \mathrm{s}\right)$ is the generation flow of the upstream reservoir $i-1$.

(2) Water-balance constraint (Equation (8)):

$$
V_{i, t}=V_{i, t-1}+\left(I_{i, t}-O_{i, t}\right) \cdot \Delta t
$$

where $V_{i, t}\left(\mathrm{~m}^{3}\right)$ is the storage of reservoir $i$ in time $t$.

(3) Water-level constraints (Equations (9) and (10)):

$$
Z_{i, t}^{\min } \leq Z_{i, t} \leq Z_{i, t}^{\max }
$$




$$
\left|Z_{i, t}-Z_{i, t-1}\right| \leq Z_{i, t}^{\text {step }}
$$

where $Z_{i, t}^{\min }(\mathrm{m})$ and $Z_{i, t}^{\max }(\mathrm{m})$ are the lower and upper bounds of the water level, respectively; and $Z_{i}^{\text {step }}(\mathrm{m})$ is the limitation of the water-level variation.

(4) Outflow constraint (Equation (11)):

$$
O_{i, t}^{\min } \leq O_{i, t} \leq O_{i, t}^{\max }
$$

where $O_{i, t}^{\min }\left(\mathrm{m}^{3} / \mathrm{s}\right)$ and $O_{i, t}^{\max }\left(\mathrm{m}^{3} / \mathrm{s}\right)$ are the minimum and maximum outflows of reservoir $i$, respectively.

(5) Output constraint (Equation (12)):

$$
N_{i, t}^{\min } \leq N_{i, t} \leq N_{i, t}^{\max }
$$

where $N_{i, t}^{\min }(\mathrm{kW} \cdot \mathrm{h})$ and $N_{i, t}^{\max }(\mathrm{kW} \cdot \mathrm{h})$ are the minimum and maximum power output of reservoir $i$, respectively.

(6) Boundary condition (Equation (13)):

$$
Z_{i, 0}=Z_{i, \text { start }}, Z_{i, T}=Z_{i, \text { end }}
$$

where $Z_{i, \text { start }}(\mathrm{m})$ and $Z_{i, \text { end }}(\mathrm{m})$ are the initial and terminal water levels of reservoir $i$, respectively.

\subsubsection{Solution Encoding and Initialization}

When applying the MoCS to address multi-objective power generation scheduling, the water levels or outflows of the hydropower stations are often chosen as the decision variable. In the present study, the water level was employed, and encoded as (Equation (14)):

$$
Z=\left[\begin{array}{c}
Z_{1} \\
Z_{2} \\
\cdots \\
Z_{N}
\end{array}\right]=\left[\begin{array}{c}
z_{1}^{1}, \cdots z_{1}^{d}, \cdots z_{1}^{T} \\
z_{2}^{1}, \cdots z_{2}^{d}, \cdots z_{2}^{T} \\
\cdots \\
z_{N}^{1}, \cdots z_{N}^{d}, \cdots z_{N}^{T}
\end{array}\right]
$$

where $z_{i}^{d}(\mathrm{~m})$ is the water level at hydropower station $i$ and time $d$. The initial value of $z_{i}^{d}$ is randomly generated as:

$$
z_{i}^{d}=z_{i}^{\min }+R A N D(0-1) \cdot\left(z_{i}^{\max }-z_{i}^{\text {min }}\right)
$$

where $R A N D(0-1)$ is a randomly generated value between 0 and 1 ; and $z_{i}^{\max }(\mathrm{m})$ and $z_{i}^{\min }$ (m) are the upper and lower boundaries of reservoir $i$, respectively. When a new individual is randomly generated, there is a high probability that it will not meet the constraints, and it will be replaced with new individuals until the new individuals meet the constraints.

In the evolution stage, the individual does not meet the constraints and is corrected by adjusting the water level to the feasible range as follows:

$$
z_{i}=\left\{\begin{array}{c}
z_{i}^{\text {min }}, \text { if } z_{i}<z_{i}^{\text {min }} \\
z_{i}^{\text {max }}, \text { if } z_{i}>z_{i}^{\text {max }} \\
z_{i}, \text { otherwise }
\end{array}\right.
$$

where $z_{i}^{\min }$ and $z_{i}^{\max }$ are determined by the water level, outflow, and power output constraints, respectively according to Equations (17)-(19):

$$
\begin{gathered}
z_{i}^{\text {max }}=\min \left(z_{i-1}+\triangle z^{\text {max }}, Z\left(z_{i-1}, Q_{i}^{\text {min }}\right), Z\left(z_{i-1}, Q_{i}^{P \min }\right), z^{\text {max }}\right) \\
z_{i+1}^{\text {min }}=\max \left(z_{i}-\triangle z, Z\left(z_{i}, Q_{i}^{\text {max }}\right), z^{\text {min }}\right)
\end{gathered}
$$




$$
Z\left(z_{i}, Q_{i}\right)=Z\left(V\left(z_{i}\right)+\left(I_{i}-Q_{i}\right) \Delta t\right)
$$

where $Q_{t}^{\min }\left(\mathrm{m}^{3} / \mathrm{s}\right)$ and $Q_{t}^{\max }\left(\mathrm{m}^{3} / \mathrm{s}\right)$ are the minimum and maximum outflows of the reservoir; $Q_{t}^{P \min }\left(\mathrm{m}^{3} / \mathrm{s}\right)$ is the minimum outflow for a guaranteed output; $\Delta z(\mathrm{~m})$ is the limitation of the water-level change, $Z(V)$ and $V(Z)$ are the relationship between the water level and the storage.

A combination of forward and reverse corrections was used when applying the correction to an unfeasible range. First, the water level was adjusted from time period 1 to $\mathrm{T}$. If the correction failed midway, attempts were made to correct the water level from period $\mathrm{T}$ to the breakpoint. If the correction was unsuccessful, the fitness of the individual was marked as 0 .

\subsubsection{Gradient Search Strategy}

Following the gradient search strategy of the MoCS algorithm, the solution was adjusted by a small gradient, as shown in Figure 3. If the water level of a reservoir changed, both its power generation capacity and its downstream reservoirs changed.

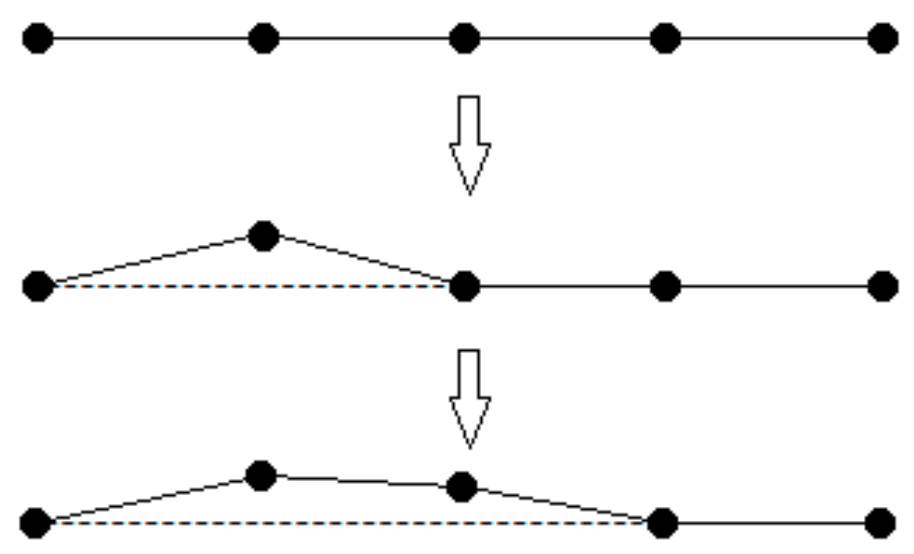

Figure 3. Gradient search strategy.

$$
\left\{\begin{array}{l}
Z_{i, t}^{\text {adjust }}=Z_{i, t}+\Delta l \\
\Delta Q_{i, t}=\left(V_{i}\left(Z_{i, t}+\Delta l\right)-V_{i}\left(Z_{i, t}\right)\right) / \Delta T_{t} \\
\Delta H_{i, t}=\Delta l / 2-Z d_{i}\left(Q_{i, t}+\Delta Q_{i, t}\right)+Z d_{i}\left(Q_{i, t}\right) \\
\Delta P_{i, t}=k_{i}\left(Q_{i, t}+\Delta Q_{i, t}\right)\left(H_{i, t}+\Delta H_{i, t}\right)-k_{i} Q_{i, t} H_{i, t}
\end{array}\right.
$$

Accordingly, the partial derivative of power generation $E(\mathrm{~kW} \cdot \mathrm{h})$, with respect to gradient $\Delta l$ is (Equation (21)):

$$
\frac{\partial E}{\partial l}=\Delta T_{t} \frac{\partial P_{i, t}}{\partial l}+\Delta T_{t+1} \frac{\partial P_{i, t+1}}{\partial l}+\sum_{j=i+1}^{N}\left(\Delta T_{t} \frac{\partial P_{j, t}}{\partial l}+\Delta T_{t+1} \frac{\partial P_{j, t+1}}{\partial l}\right)
$$

where if $\frac{\partial E}{\partial l}>0$, the water level is adjusted by $\Delta l$; otherwise, the adjustment is rejected. Detail derivation process can be found in [35]. A flowchart of the gradient-based search strategy for the cascade system is shown in Figure 4.

\subsubsection{Single Entry External Archive}

Elite individuals were inserted into the concept of an external archive that was introduced in the MoCS algorithm. When the number of individuals in the archive exceeded the limit, the non-optimal solution was removed based on the non-dominated sorting and crowding degree calculation. 


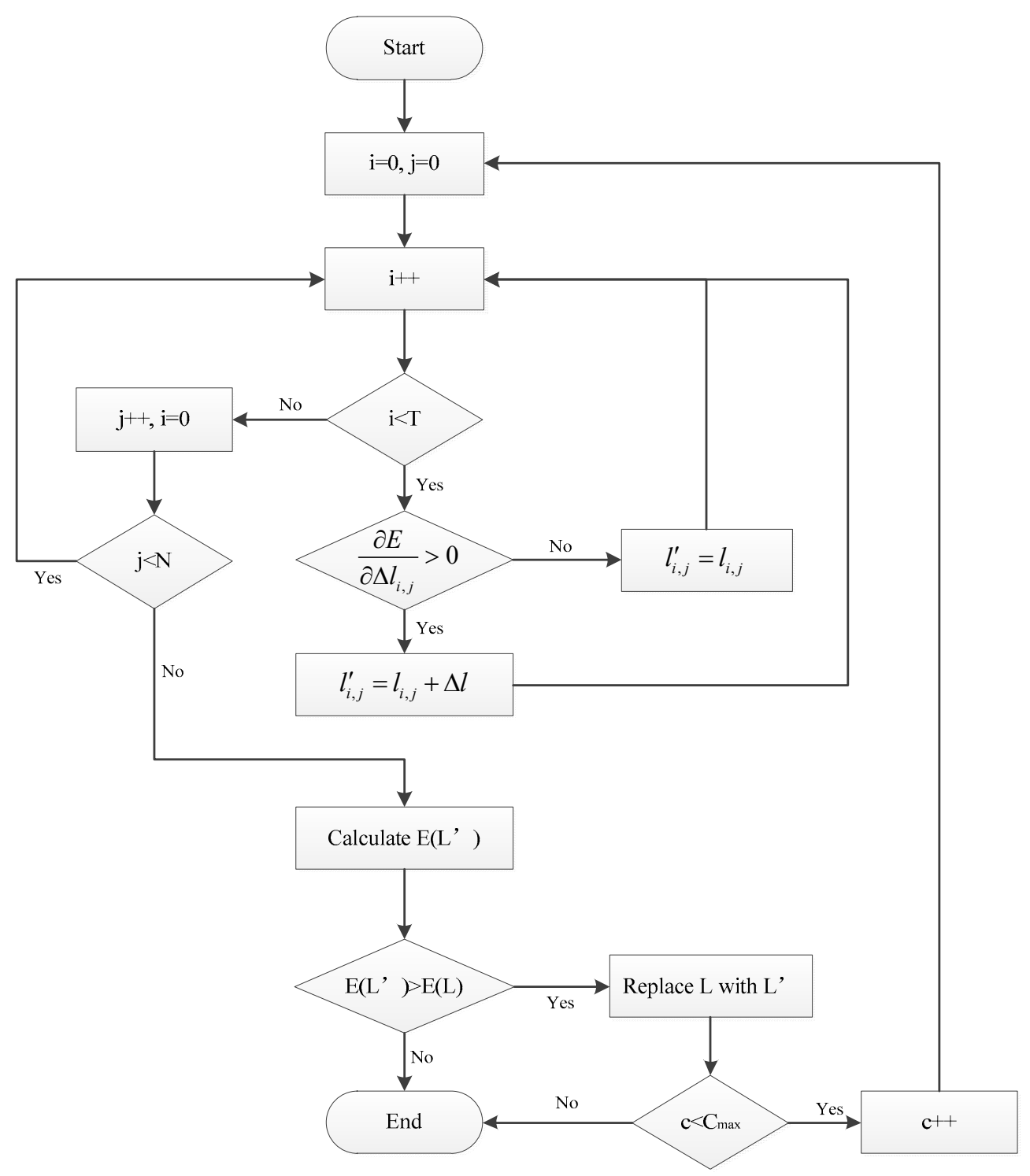

Figure 4. Flowchart of gradient-based search strategy.

Notably, if all of the elite individuals were inserted into the external archive at the same time, some may be concentrated. The crowding degrees of these individuals will be small, and there is a high probability that they will be removed during selection, which is not conducive to the generation of the Pareto front. Therefore, it was necessary to insert only one elite individual at a time, with the subsequent individual inserted only after the selection was completed. The Pareto optimal front will be more uniform following this strategy shown in Figure 5.

\subsubsection{Self-Tuning Divergent Operator Strategy}

A divergent operator strategy was introduced to increase population diversity. During new individual generation, a certain number from the population were randomly selected and underwent single-objective evolution separately. Simultaneously, the remaining individuals executed the original evolution selection strategy.

The number of individuals performing single-target evolution $(n)$ was determined by the number of targets (Figure 6). If the objective maximum changed, the amount of the corresponding single-target individuals increased, and if no change was observed, this number decreased. The purpose of this strategy was to expand the algorithm's ability to search for edges. 


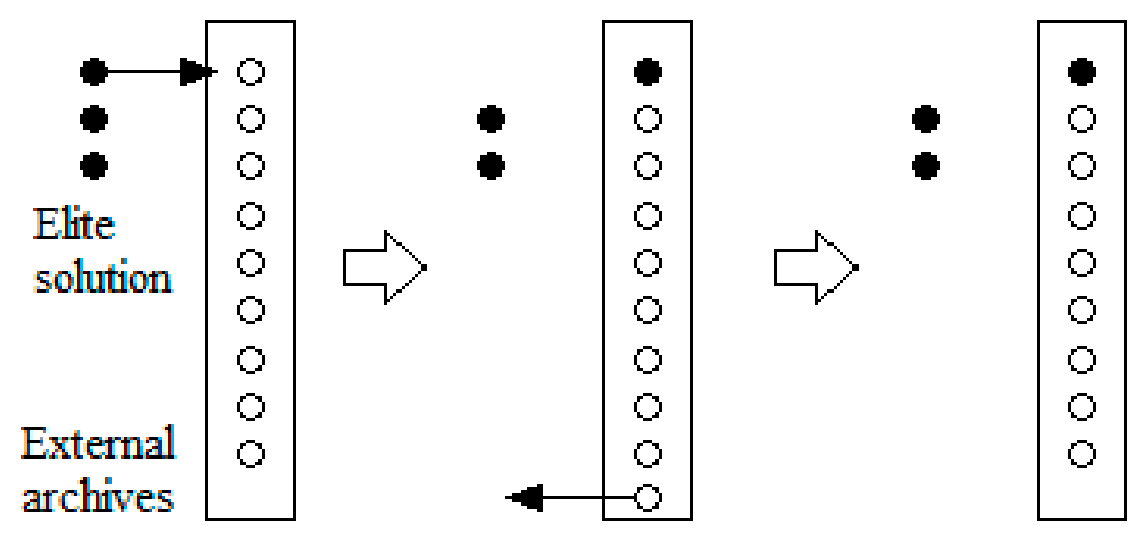

Figure 5. Single entry external archive.

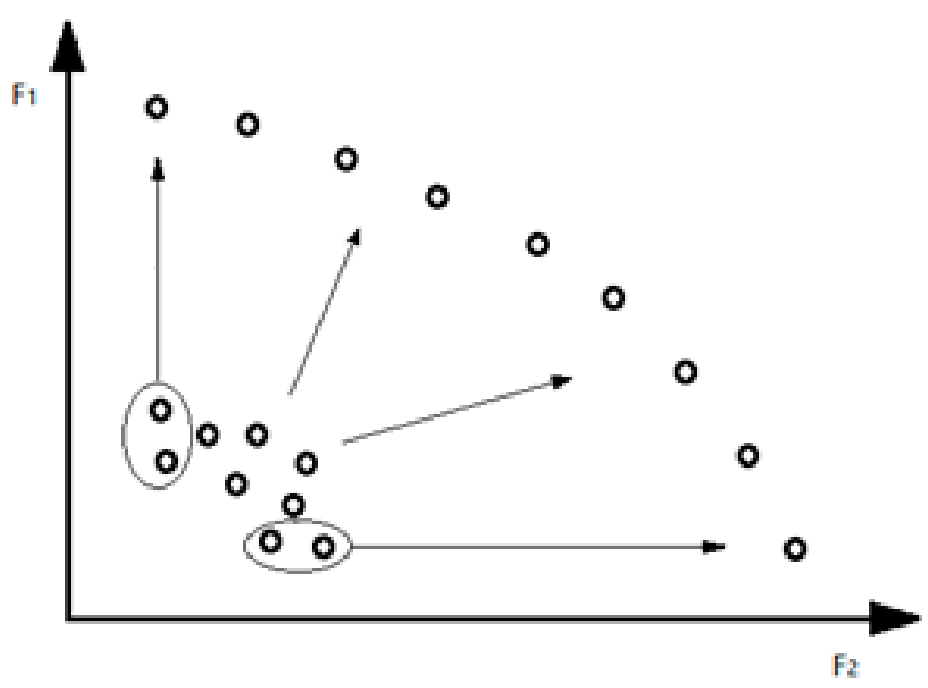

Figure 6. Self-tuning divergent operator strategy.

\subsubsection{Procedures of Solving MLTHG with Gradient Based MoCS}

Accordingly, the procedures of solving MLTHG with Gradient based MoCS (GMoCS) were as follows (Figure 7):

(1) Set the initial conditions of the MLTHG model, including incoming water, water level of each hydropower station in the initial time period and the end time period.

(2) Set up the constraints of the MLTHG model, including the maximum outflow, minimum outflow, maximum water level, minimum water level, and water level variation in each period of each hydropower station. The setting of water level constraints needs to consider the flood control requirements in the flood season.

(3) Set the parameters of the GMoCS algorithm.

(4) Generate a random individual according to Equations (14) and (15), calculate its objective values and check whether it meets all constraints. If the constraints are met, added it to the initial population. Generate other new individuals using the same method until the population size is reached.

(5) Generate new individual by Lévy flight.

(6) Calculate objective values of the new individual and check whether it meets all constraints. If the new individual does not meet the constraints, try to adjust the water level to make it meet the constraints.

(7) Mix the old and new populations. Perform non-dominated sorting and crowding calculations on the mixed population. Select better individuals to form the next generation population. 
(8) Select the individual with the largest power generation and perform gradient search for the power generation objective. Then, select the individual with the smallest residual load variance, and perform gradient search for the residual load variance objective.

(9) Select non-dominated individuals from the next generation population. Insert the non-dominated individuals into the external archives one by one, while replacing the worst individual with a better random individual with a certain probability.

(10) Repeat steps 3-9 until the termination condition is met.

(11) Select non-dominated individuals from the external archive set as the Pareto optimal frontier. Export time series data of these individuals, including water level, outflow, power output, etc.

\subsection{MLTHG in Jinsha River}

\subsubsection{The Projection of Streamflow in the Context of Climate Change}

The historical observed daily precipitation and temperature (maximum and minimum) data are collected from China's Ground Precipitation $0.5^{\circ} \times 0.5^{\circ}$ Gridded Dataset (V2.0) and China's Ground Temperature $0.5^{\circ} \times 0.5^{\circ}$ Gridded Dataset (V2.0) (http:/ / data.cma.cn/ accessed on 25 May 2021), respectively. The dataset covers 2474 national meteorological stations over the Chinese mainland. It consists of a series of daily observed data from 1961 to the present. We use data from 208 grid boxes associate with the Jinsha River, shown in Figure 8.

The future climate change scenarios are obtained from the Inter-Sectoral Impact Model Intercomparison Project (ISI-MIP) [36]. Continuous daily precipitation and temperature data on a horizontal grid with $0.5^{\circ} \times 0.5^{\circ}$ resolution for the period 1960-2099 were offered by five GCMs, including GFDL-ESM2M, HADGEM2-ES, IPSL-CM5A-LR, MIROC-ESMCHEM, and NORESM1-M. Output of the climate model was spatially interpolated using a bilinear interpolation method, and the data has already been bias-corrected using a trendpreserving bias correction method [37]. The bias correction method modifies the monthly mean and daily variability of the simulated data to match the observations. Change of average daily precipitation and temperature (maximum and minimum) between each GCM and observations are shown in Figures 9-11.

The main hydrological model used for streamflow forecasting is the Xinanjiang (XAJ) model. The daily precipitation of each sub-catchment is evaluated following:

$$
P=\frac{\sum_{i=1}^{N} P_{i} S_{i}}{\sum_{i=1}^{N} S_{i}}
$$

where $P$ is the average precipitation of the sub-catchment, $P_{i}$ is the precipitation of the grid box $i$, and $S_{i}$ is the area of grid box $i$. $\mathrm{N}$ is the number of grid boxes in the sub-catchment.

The daily potential evapotranspiration of each grid is calculated using Hargreaves method [38]:

$$
E T_{0}=H_{A} \cdot R_{e}(T+17.8) \cdot \Delta T^{H_{E}}
$$

where $H_{A}$ and $H_{E}$ are the parameters with standard values of 0.0023 and 0.5 , respectively. $R_{e}$ is the extraterrestrial radiation. $T$ is the mean temperature $\left(T=\left(T_{\max }+T_{\min }\right) / 2\right)$ and $\Delta \mathrm{T}$ is the air temperature range $\left(\Delta T=T_{\max }-T_{\min }\right)$. The daily evapotranspiration of each sub-catchment is calculated in the same way with precipitation.

The parameters of XAJ model are calibrated using the observed hydrological data and the calibrate method is based on ICS. The outflow of each sub-catchment is routed using the Muskingum method. The precipitation and temperature data from 1961 to 2050 given by five GCMs in three different scenarios (RCP2.6, RCP4.5, RCP8.5) was input to the parameterized XAJ model, and the daily streamflow in the context of climate change can be simulated. Detailed prediction methods can be found in [39]. 


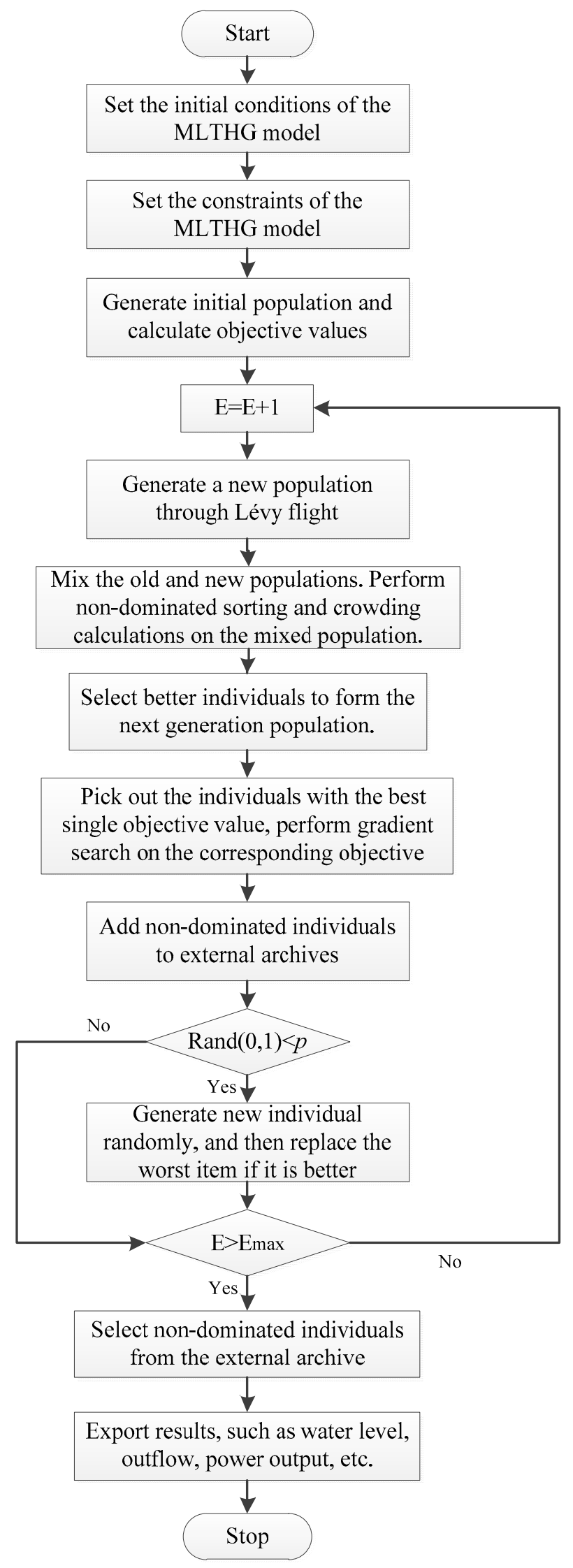

Figure 7. Flowchart of GMoCS for solving MLTHG. 


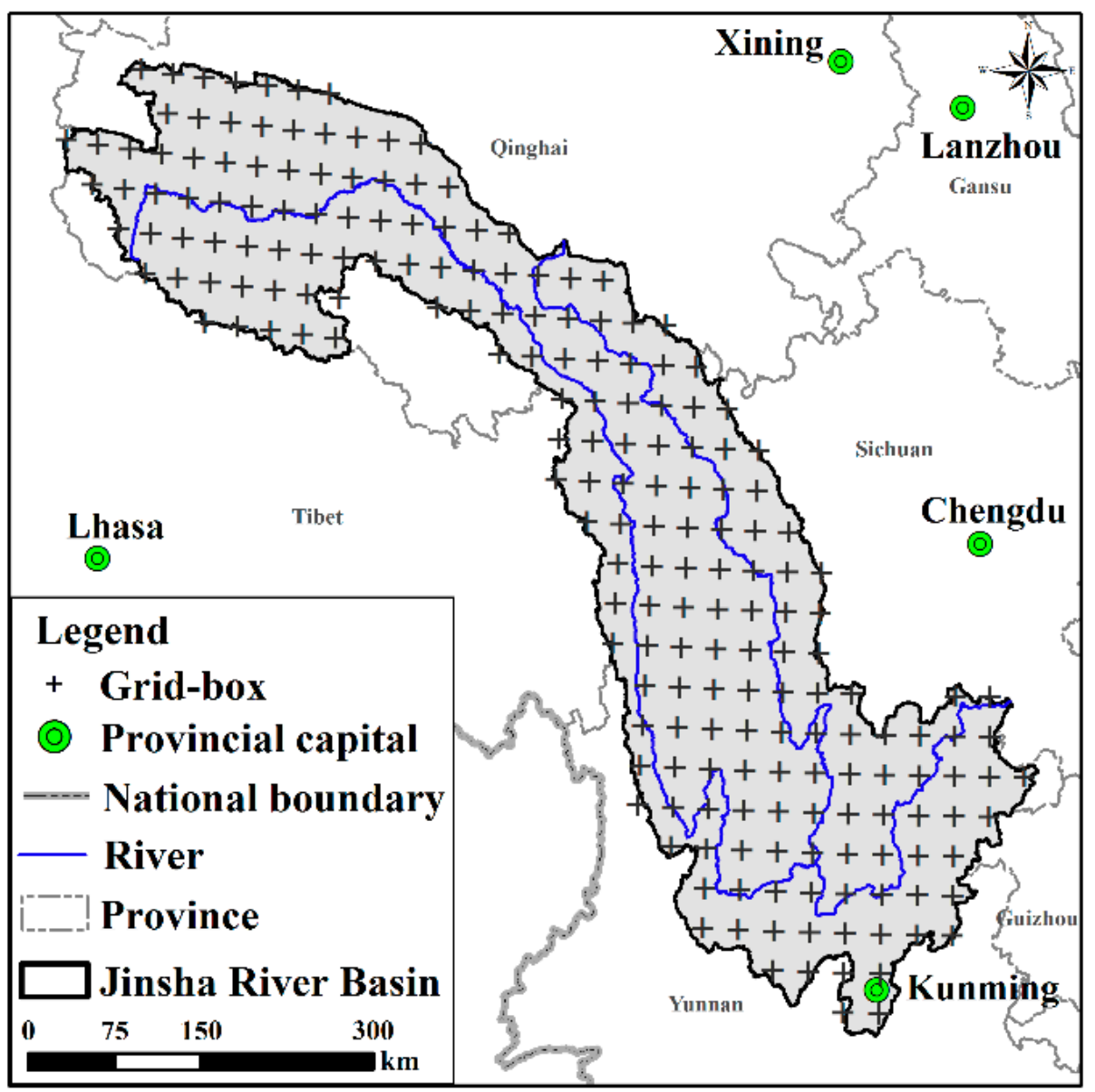

Figure 8. Locations of major cities and hydrological stations along the Jinsha River.

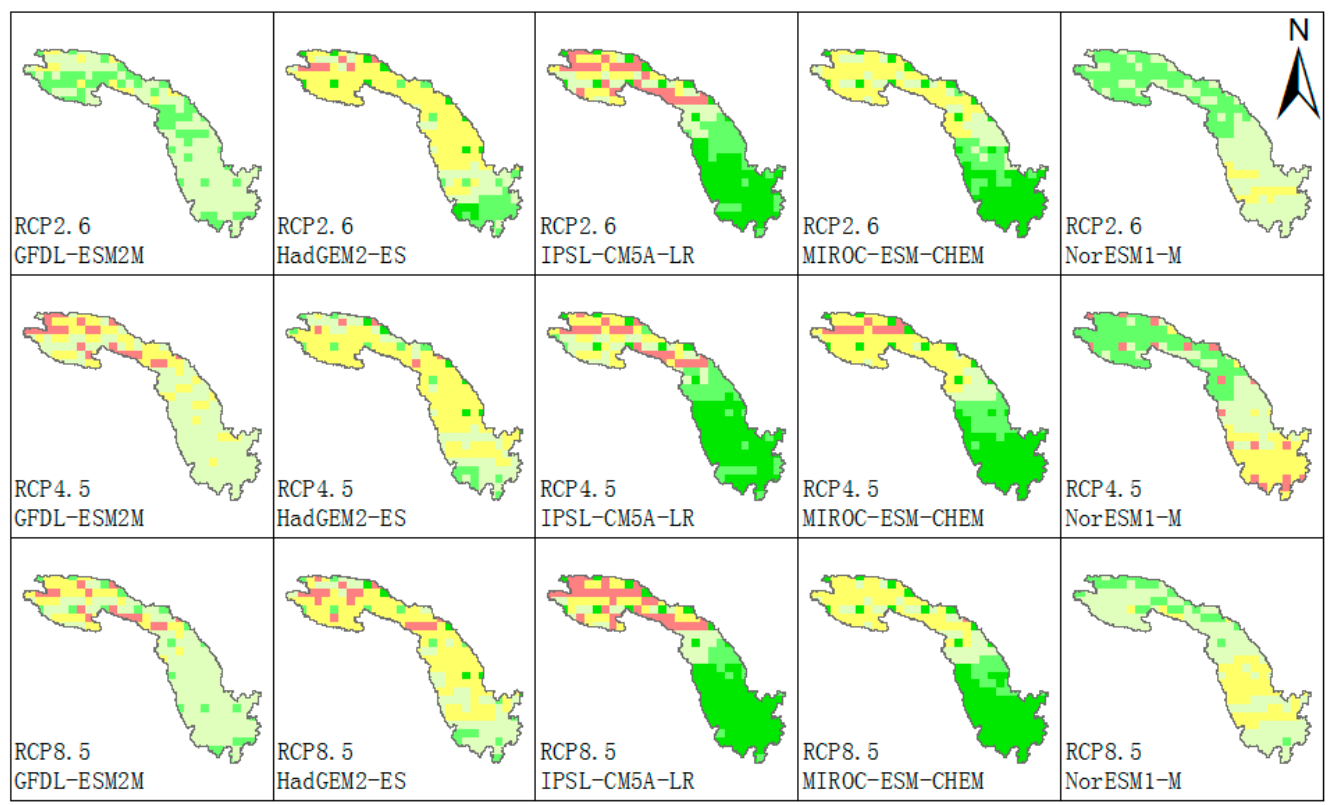

Change of Precipitation (\%)

$$
\square<-5 \quad-5 \text { to } 0 \quad 0 \text { to } 5 \quad 5 \text { to } 10 \backsim>10
$$

Figure 9. Change of precipitation. 


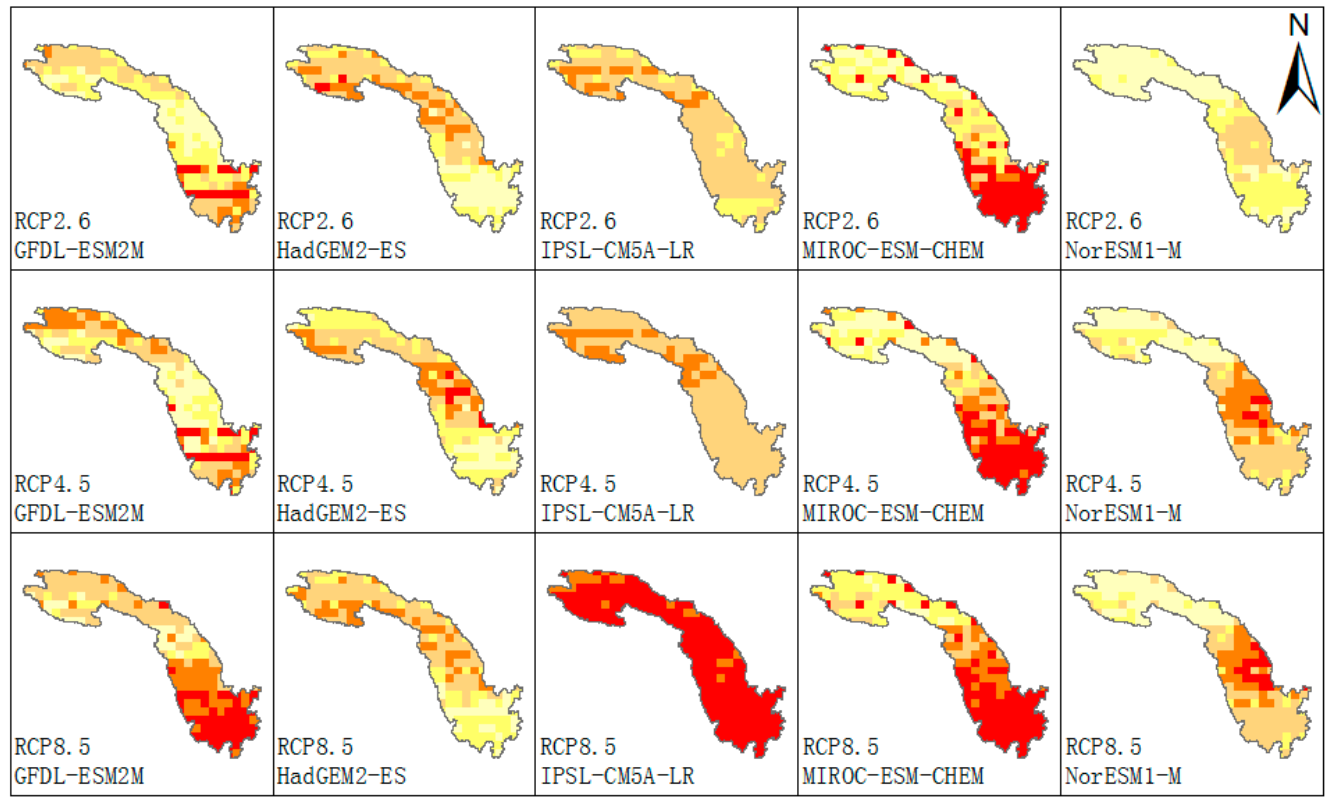

Change of Maximum Temperature

0 to $1.15 \quad 1.15$ to $1.35 \quad 1.35$ to $1.55 \square 1.55$ to $1.75 \square>1.75$

Figure 10. Change of maximum temperature.

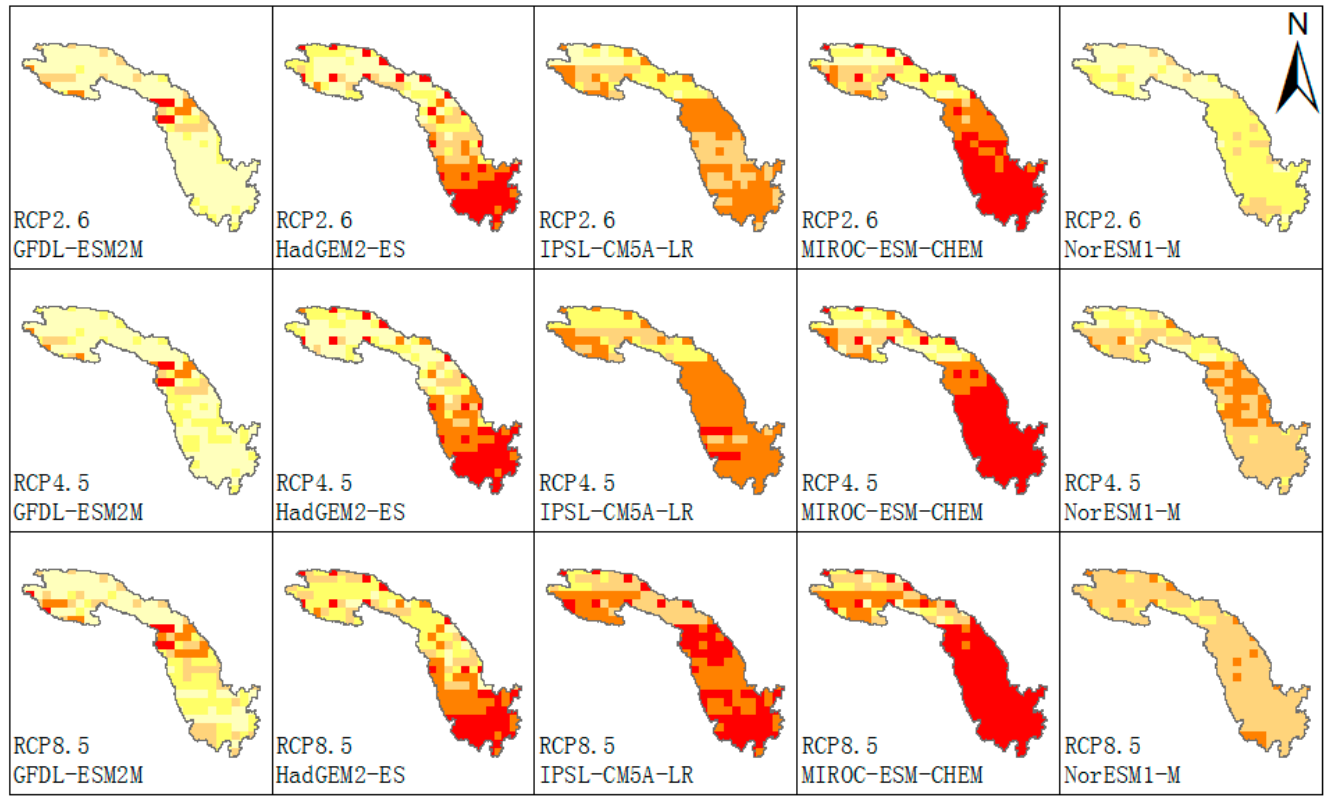

Change of Minimum Temperature $\left({ }^{\circ} \mathrm{C}\right)$

\section{0 to $1.1 \quad 1.1$ to $1.3-1.3$ to $1.6-1.6$ to $2.2 \square>2.2$}

Figure 11. Change of minimum temperature.

\subsubsection{Modeling of MLTHG in Jinsha River}

The Jinsha River is in the upper reaches of the Yangtze River. It is born at the junction of Qinghai and Sichuan Province, and ends at the mainstream of the Yangtze River in Yibin. There is strong hydrological potential along the river, particularly in the lower reaches where elevation decreases dramatically. Four large cascade hydropower stationWudongde, Baihetan, Xiluodu, and Xiangjiaba-are located along the lower reaches of the river (Figure 12). The main primary station parameters are listed in Table 1, and the topology structure is shown in Figure 13. 


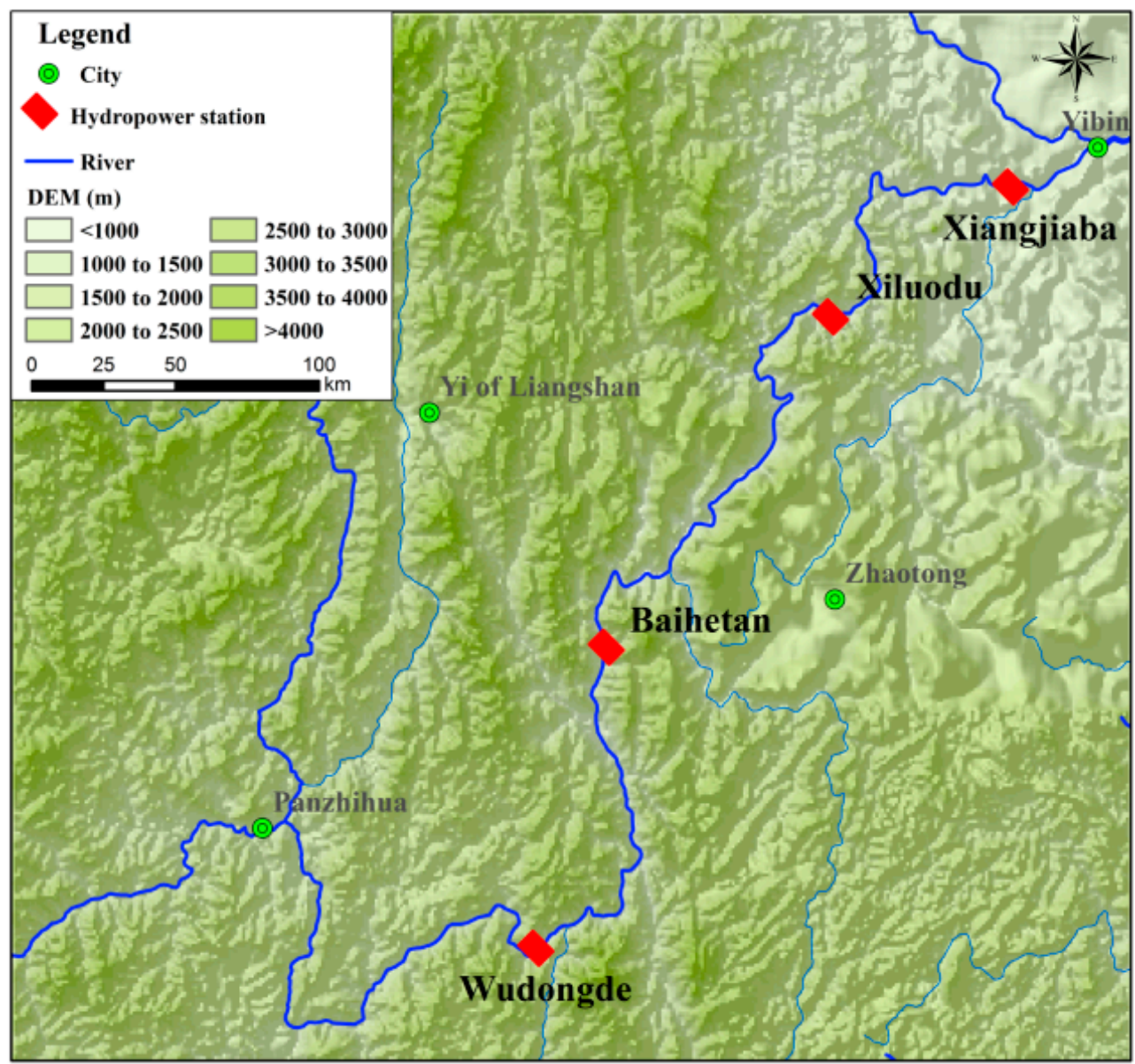

Figure 12. Locations of major cities and hydrological stations along the Jinsha River.

Table 1. Main parameters of the four cascade hydropower stations along the lower reaches of the Jinsha River.

\begin{tabular}{ccccc}
\hline Parameters & Wudongde & Baihetan & Xiluodu & Xiangjiaba \\
\hline Dead water level $(\mathrm{m})$ & 945 & 765 & 540 & 370 \\
Normal water level $(\mathrm{m})$ & 977 & 825 & 600 & 380 \\
Flood limit water level $(\mathrm{m})$ & 952 & 785 & 560 & 370 \\
Installed capacity $\left(10^{4} \mathrm{kw}\right)$ & 1020 & 1600 & 1260 & 600 \\
Total capacity $\left(10^{8} \mathrm{~m}^{3}\right)$ & 74.08 & 206.27 & 126.7 & 51.63 \\
Minimum outflow $\left(\mathrm{m}^{3} \cdot \mathrm{s}^{-1}\right)$ & 906 & 905 & 1500 & 1500 \\
\hline
\end{tabular}

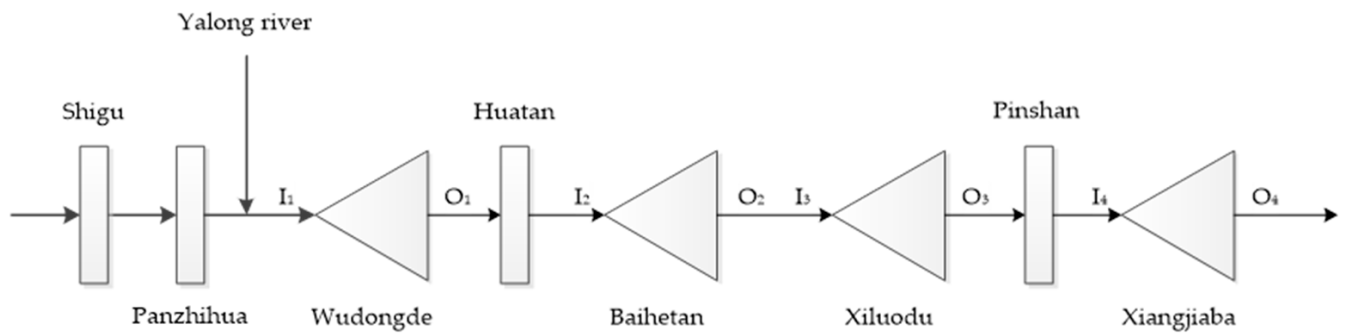

Figure 13. Topology of hydrological stations in the Jinsha River.

There are two hydrological stations in the basin-Huatan and Pinshan, and the streamflow of the four hydropower stations was projected using the Xinanjiang model. The inflow of Wudongde was generalized using the streamflow of the Huatan station, and 
the interval inflow between Baihetan and Xiluodu was generalized using the streamflow of the Pingshan station according to Equations (22) and (23):

$$
\begin{gathered}
I_{1}=Q_{\text {Huatan }} \\
\Delta I_{3}=Q_{\text {Pingshan }}-Q_{\text {Huatan }}
\end{gathered}
$$

The power generation at time $t$ can be obtained by Equation (24):

$$
E_{i, t}=k_{i} Q_{i, t} H_{i, t} \Delta t
$$

where $E_{i, t}(\mathrm{~kW} \cdot \mathrm{h})$ is the hydropower generation of reservoir $i$ at time $t ; Q_{i, t}\left(\mathrm{~m}^{3} / \mathrm{s}\right)$ is the generation flow through the hydropower units of reservoir $i$ at time $t ; k_{i}$ is the comprehensive benefit coefficient of reservoir $i$, which reflects the hydro-generating unit efficiency; $\Delta t$ is the length of time interval, and $H_{i, t}(\mathrm{~m})$ is the net water head of reservoir $i$ at time $t$, defined by Equation (25):

$$
H_{i, t}=\frac{Z_{i, t-1}+Z_{i, t}}{2}-Z d_{i, t}-\Delta H_{i}
$$

where $Z_{i, t-1}(\mathrm{~m})$ and $Z_{i, t}(\mathrm{~m})$ are the beginning and end water levels of reservoir $i$ at time $t$, respectively; $Z d_{i, t}(\mathrm{~m})$ is the water level under the dam; and $\Delta H_{i}(\mathrm{~m})$ is the water head loss of reservoir $i$.

Overall, the objective of the MLTHG scheduling model was to find an optimal set of water releases or storage volumes to maximize the MLTHG of cascade hydropower stations, which can be described mathematically according to Equation (26):

$$
E=\max \sum_{t=1}^{T} \sum_{i=1}^{N} E_{i, t}
$$

where $E(\mathrm{~kW} \cdot \mathrm{h})$ is the total hydropower generation of the cascade reservoirs, $T$ is the number of time periods, and $N$ is the number of reservoirs.

\section{Results and Discussion}

\subsection{Performance of GMoCS}

To evaluate the performance of the GMoCS, the optimal results of the cascade hydropower stations were compared with those obtained using MoCS. The parameters of GMoCS were: $n s=40, p_{a}^{s}=0.3, p_{a}^{e}=0.1, s l=0.01, u=0, c=1.5$, and the maximum evaluation time was set to 12000 . The initial and end water levels of the reservoirs were set to their normal levels (Table 1), and each month was divided into three periods of $\sim 10$ days each, resulting in 36 time intervals per year. Each method was run 100 times, independently.

Three typical streamflows of Pingshan station (Figure 14) chosen by the annual runoff frequency curve - dry (frequency $75 \%$ ), normal (50\%), and wet (25\%) years-are used as the input of MLTHG. Water levels of the four reservoirs at different time intervals (excluding the 36th) were chosen as the optimization parameters, making the problem dimension $=140$. Equations (5) and (6) are the fitness functions of MLTHG, and the greater the power generation and the smaller the residual load variance, the better the solution. The simulation results are shown in Figure 15.

The Pareto optimal frontier obtained by GMoCS was superior to the results of MoCS (Figure 15). MoCS fell into a local optimum when solving the MLTHG; whereas the results obtained by GMoCS indicated that the strategies proposed in the present study effectively improved the algorithm's search ability. It can be seen that total power generation of the cascade hydropower stations and residual load variance of the power grid were inversely correlated. These two objectives were conflicting and mutual. The scheduling processes of the 2nd and 49th solutions of wet year are shown in Figure 16 as an example. The difference 
between the two solutions is mainly in the period before the flood season (June, July). Due to the large inflow during the flood season, the power generation will increase significantly. The 2nd solution increases the power generation capacity for a period of time before the flood season by lowering the water level in advance. This makes the growth of power generation before the flood season relatively smooth, which is conducive to reducing the residual load variance of the power grid. The 49th solution maintains high water level for the period before flood season, resulting in an increase in the total power generation. While the residual load variance of the power grid is larger than that in 2nd solution.

In this section, we focus on the trade-off between the two objectives of power generation and residual load variance. Research done by Geressu et al. [34] shows that when the financial benefit of the reservoirs is increased, the downstream release will be adversely affected. This is similar to our research. Only a compromise plan can be chosen if we consider two conflicting goals. Moreover, as explained by Zhai et al. [31], during the flood season the cascade hydropower stations are operated below flood-limiting water level in order to reserve adequate reservoir storage for flood prevention. We also considered the same restriction, the change of the water level is mainly in the non-flood season as shown in Figure 16.

\subsection{Climate Change on Multi-Objective Scheduling of Cascade Hydropower Stations}

The impact of climate change on the total power generation of the cascade hydropower stations and residual load variance of the power grid over the next 30 years was estimated. First, streamflow prediction data of Pingshan station for the years 2021-2050 were prepared (Figure 17), and prediction results were obtained by applying the CMIP5 climate data and the Xinanjiang model (detailed prediction methods can be found in [39]). Then, the multi-objective scheduling results under three climate change scenarios- RCP2.6, RCP4.5, and RCP8.5-using five climate models-GFDL-ESM2M, HADGEM2-ES, IPSL-CM5A-LR, MIROC-ESM-CHEM, and NORESM1-M - were obtained with 30 years of daily streamflow data as the input. Accordingly, 450 solution sets were obtained. Owing to the inaccuracy of the predictions of various climate models, the Pareto frontiers also showed large levels of uncertainty.

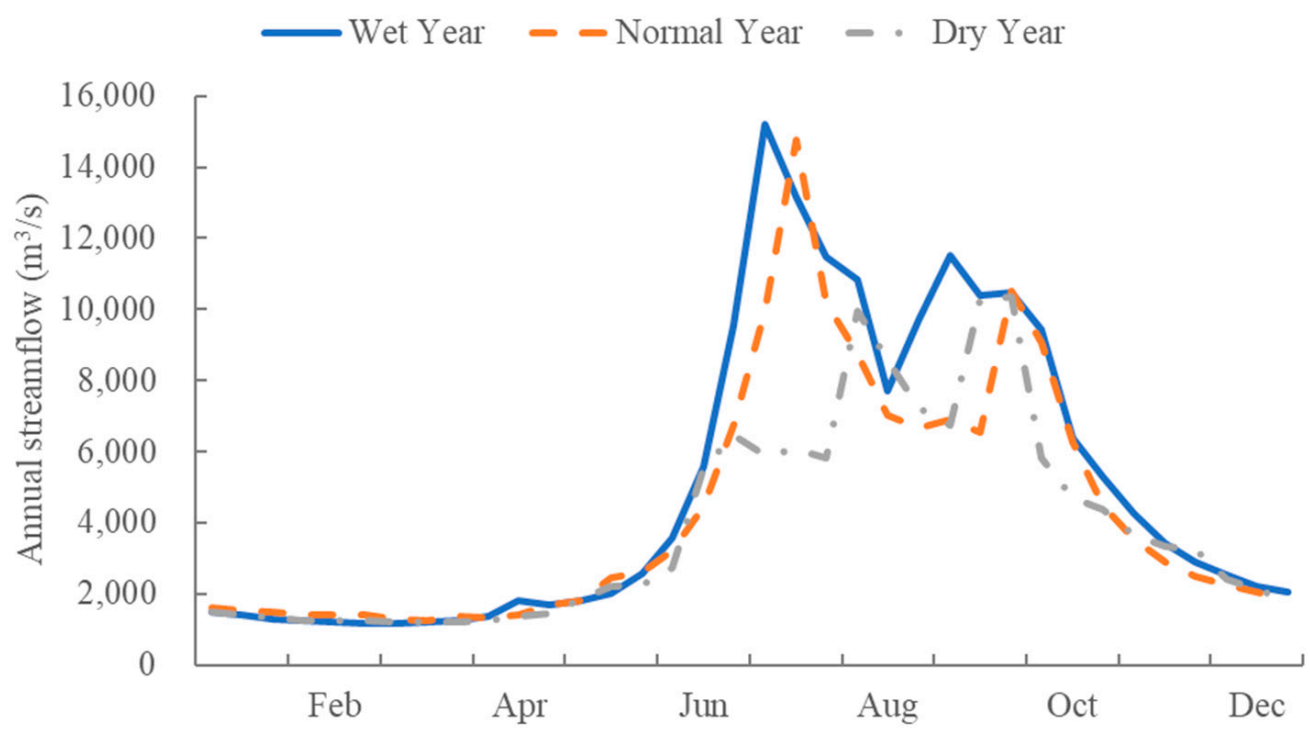

Figure 14. Three typical streamflows of Pingshan station. 


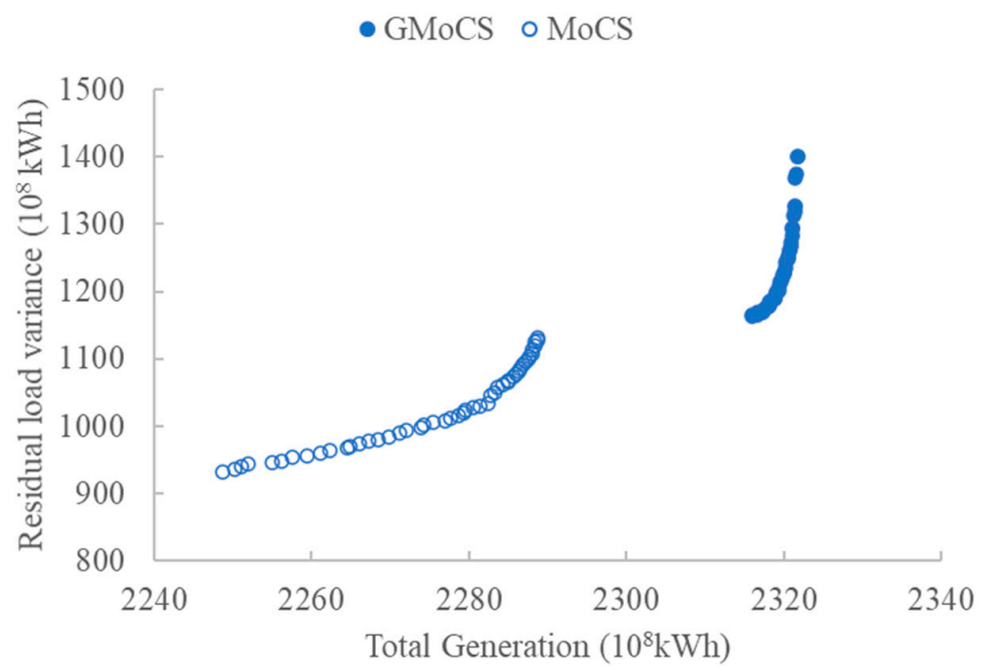

(a)

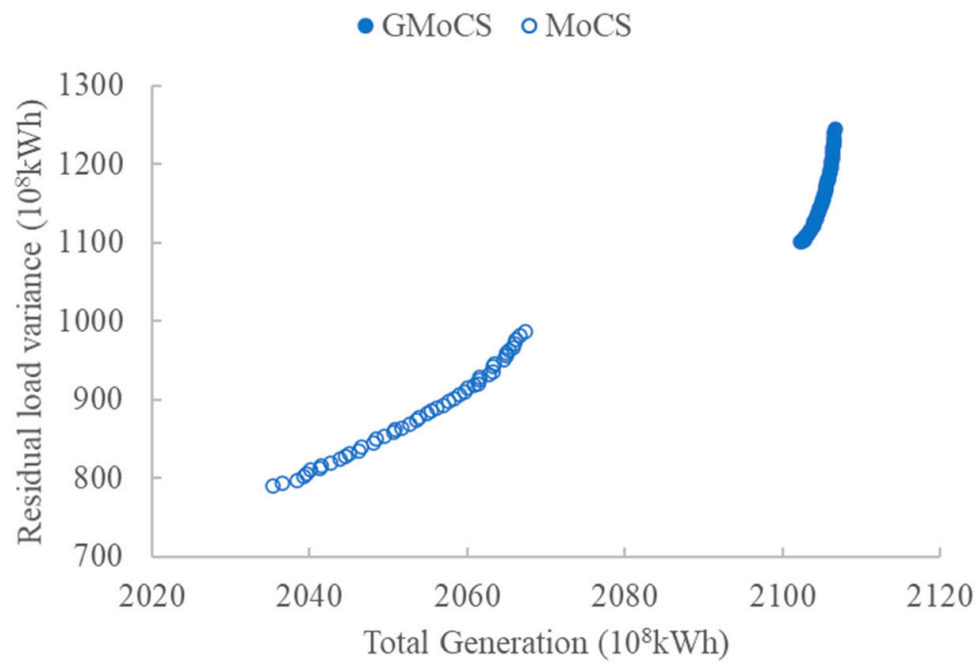

(b)

- GMoCS O MoCS

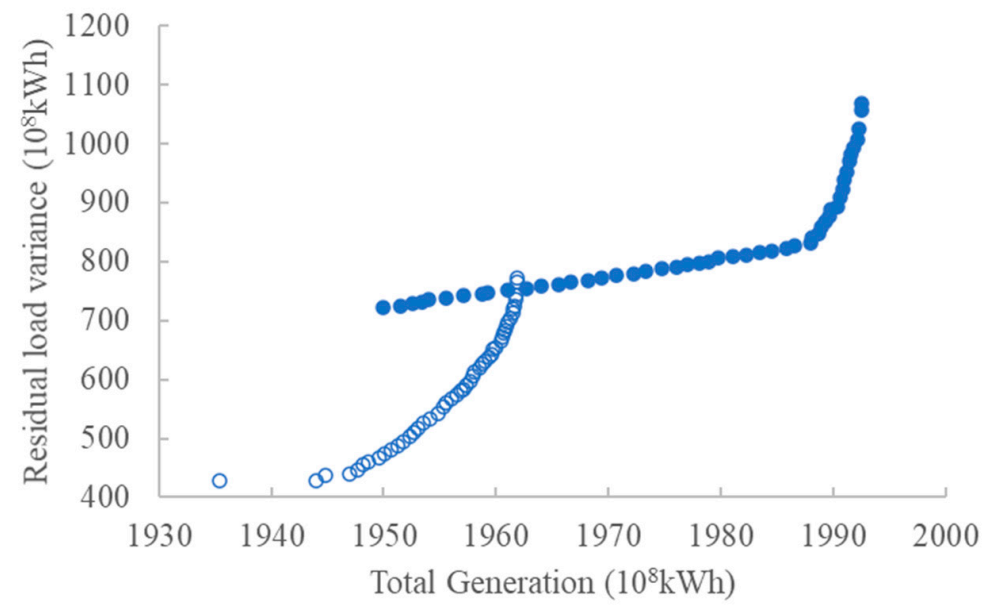

(c)

Figure 15. Optimal results obtained by MoCS and GMoCS: (a) Wet year; (b) Normal year; (c) Dry year. 


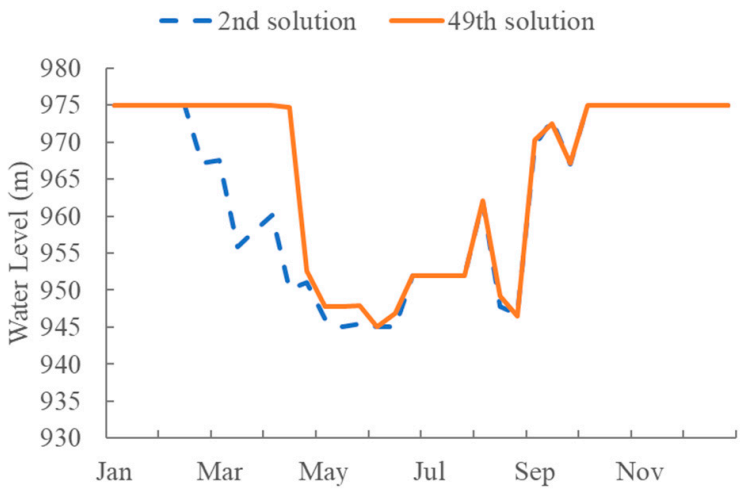

(a) Water level of Wudongde

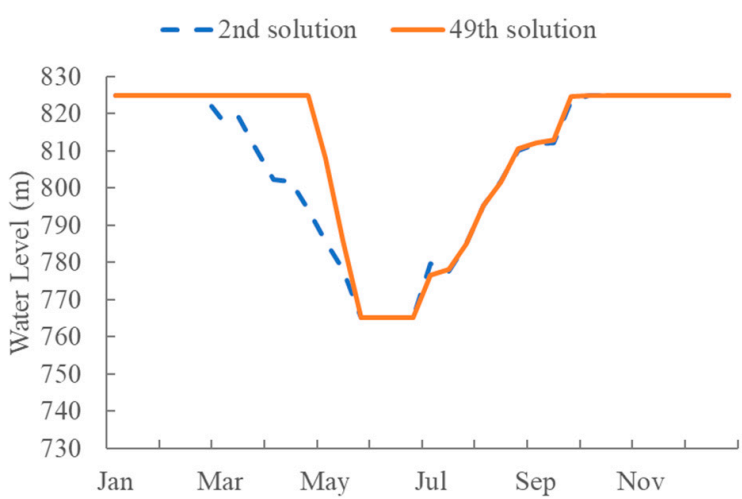

(c) Water level of Baihetan

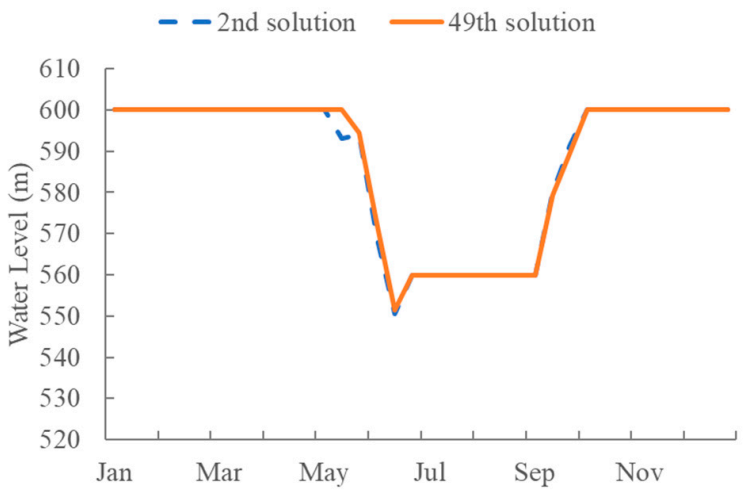

(e) Water level of Xiluodu

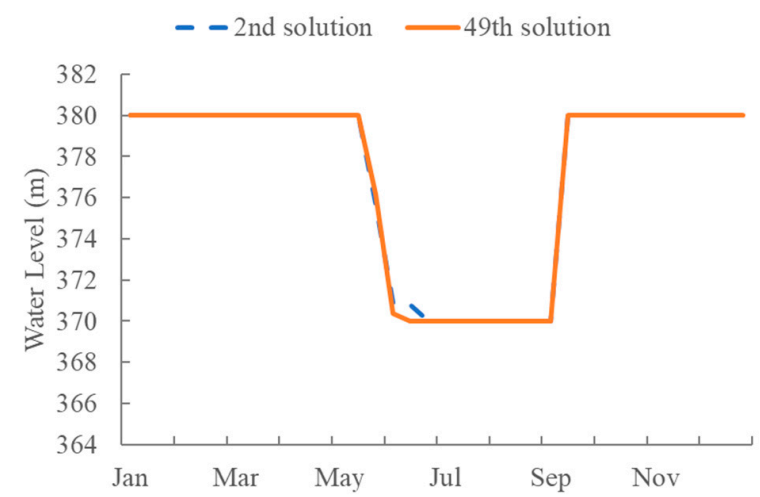

(g) Water level of Xiangjiaba

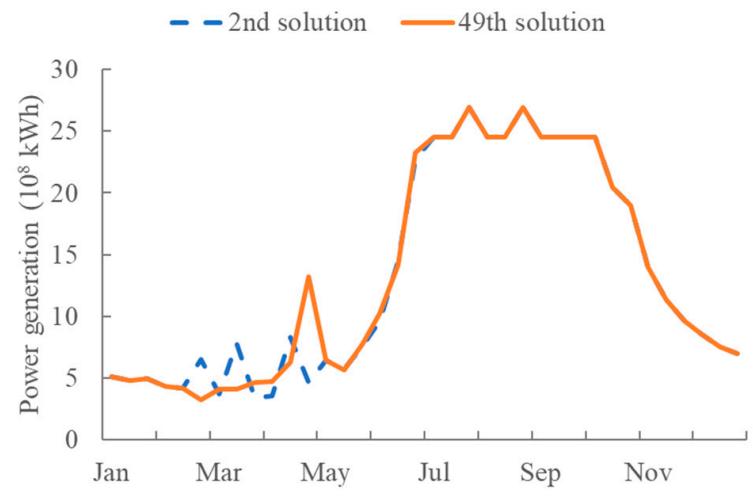

(b) Power generation of Wudongde

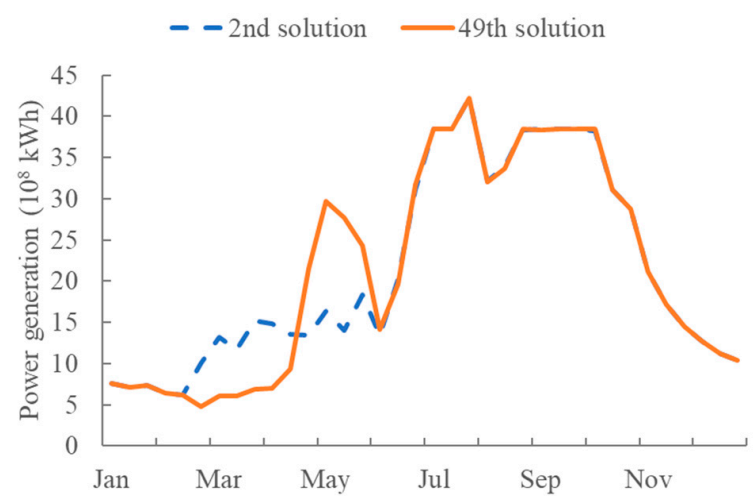

(d) Power generation of Baihetan

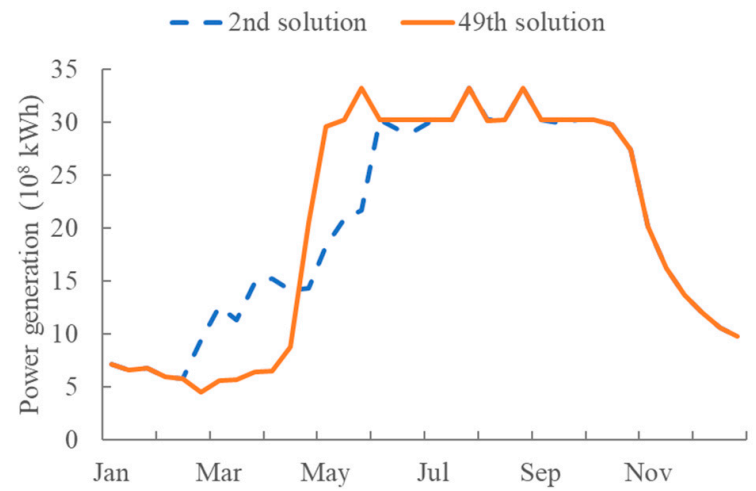

(f) Power generation of Xiluodu

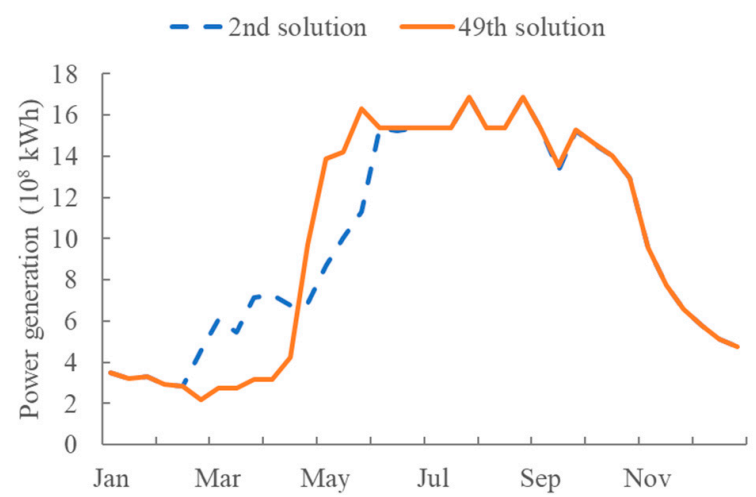

(h) Power generation of Xiangjiaba

Figure 16. Comparison between the 2nd and 49th solutions in wet year. (a) Water level of Wudongde (b) Power generation of Wudongde (c) Water level of Baihetan (d) Power generation of Baihetan (e) Water level of Xiluodu (f) Power generation of Xiluodu (g) Water level of Xiangjiaba (h) Power generation of Xiangjiaba. 


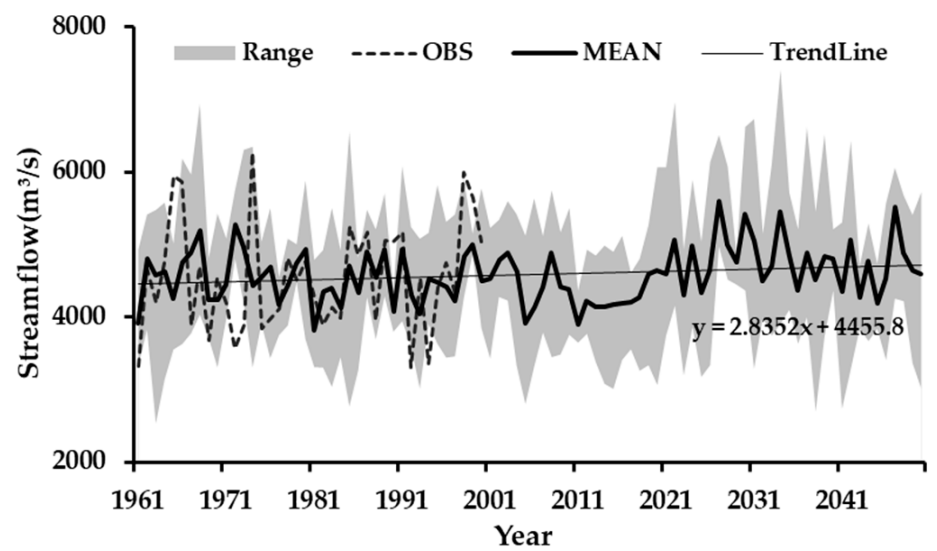

(a)

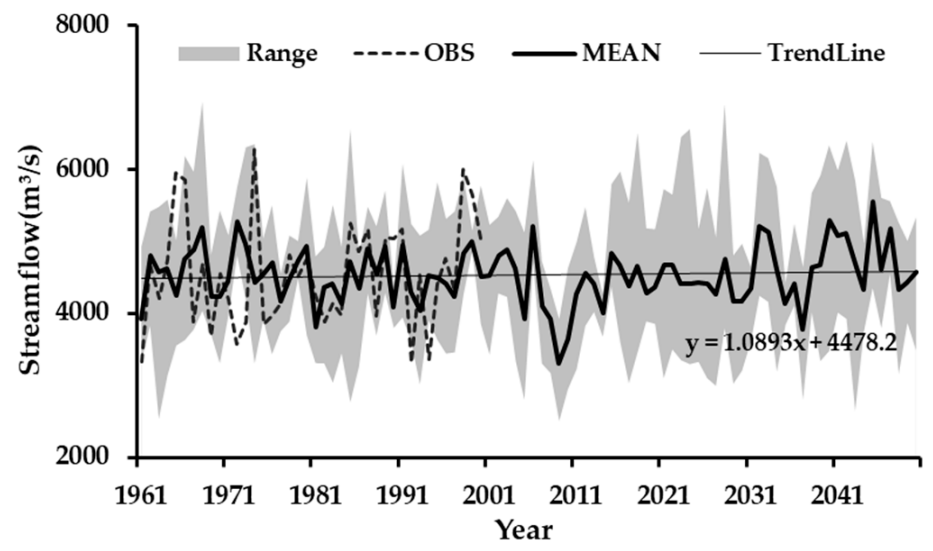

(b)

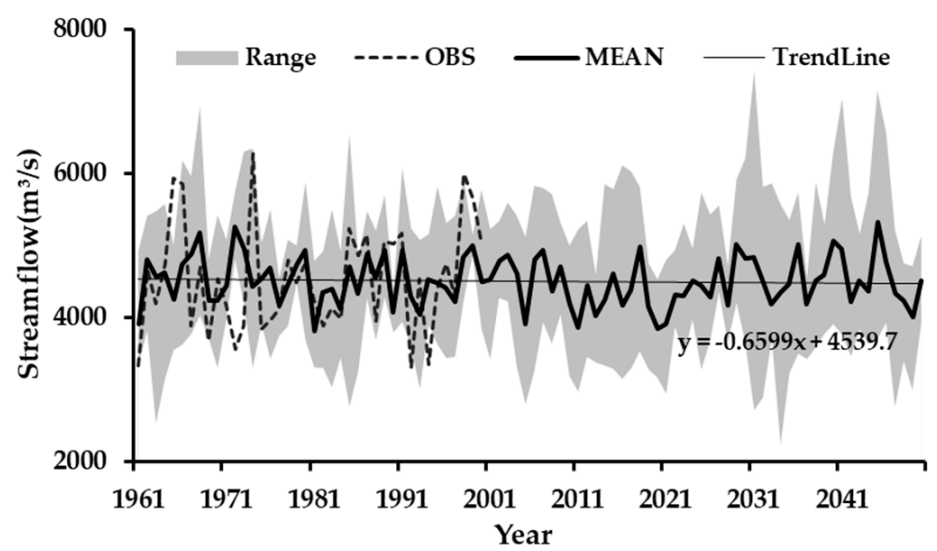

(c)

Figure 17. Annual streamflow in Pingshan Station under IPCC climate scenarios: (a) RCP2.6, (b) RCP4.5, and (c) RCP8.5.

\subsubsection{Power Generation Objective}

As explained in Section 2.3.7, the boundary of the Pareto frontier is close to that obtained through single-objective optimization. First, the optimal solution for power generation was obtained with the operator. Figure 18 displays average total power generation results per 10 years for the next 30 years under the three climate change scenarios, and Figure 18a shows the average generation results for scenario RCP2.6. The average generation results of the five GCMs were 2266,2238 , and $2188\left(10^{8} \mathrm{kWh}\right)$, respectively, while the uncertainty ranges were similar to each other: $(-4.4 \%, 4.0 \%),(-5.2 \%, 3.9 \%)$, and $(-4.3 \%, 5.4 \%)$. Figure $18 \mathrm{~b}, \mathrm{c}$ show the results under scenarios RCP4.5 and RCP8.5, which 
both displayed much larger uncertainty ratios than RCP2.6. Moreover, the average power generation in RCP2.6 was significantly larger than that in RCP8.5, and when compared with the average power generation in RCP4.5, RCP2.6 was larger for the first 20 years, but smaller following decade.

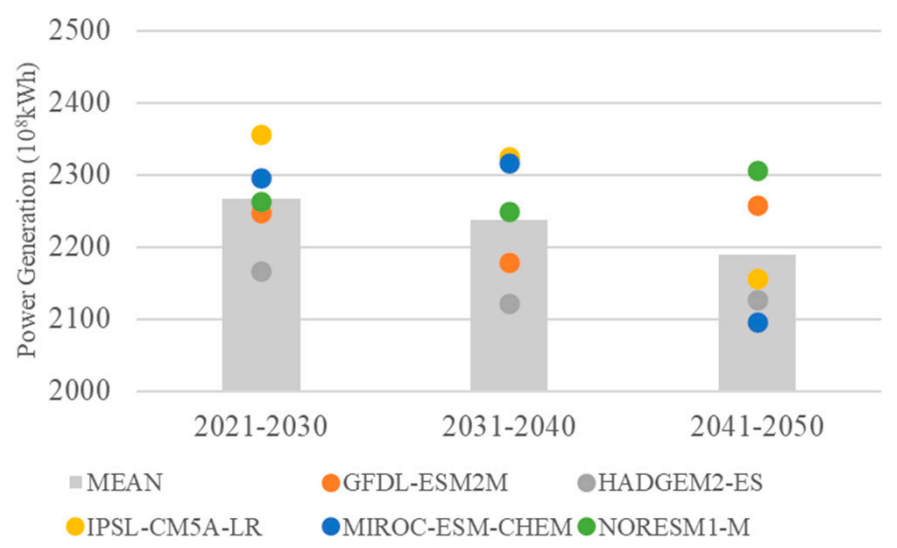

(a)

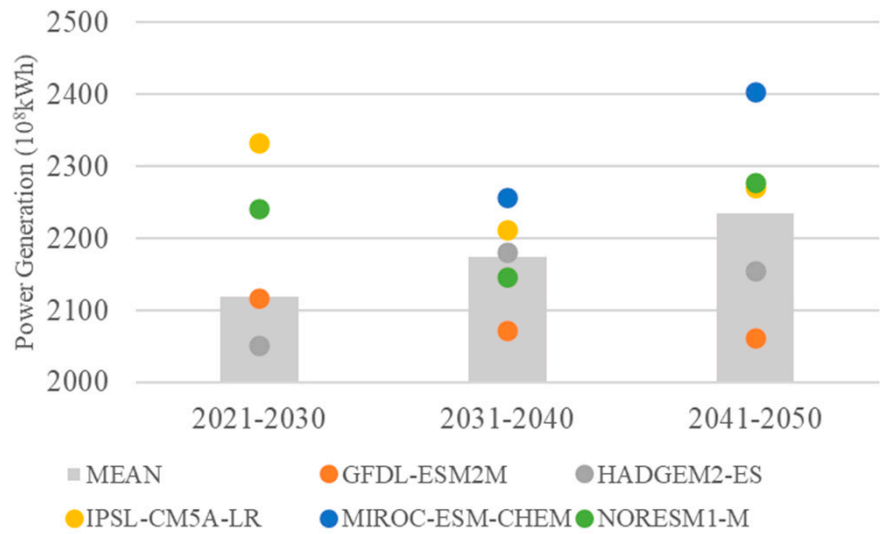

(b)

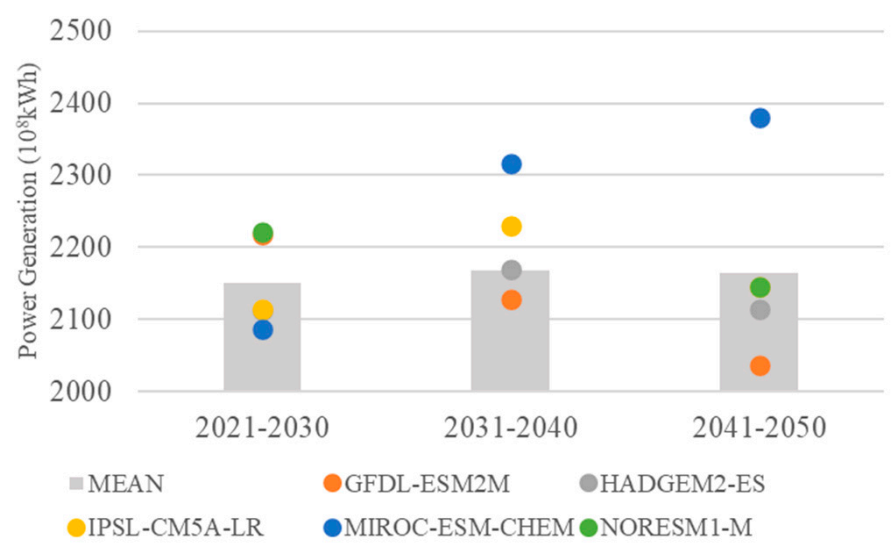

(c)

Figure 18. Power generation projections for the next three decades under scenarios: (a) RCP2.6, (b) RCP4.5, and (c) RCP8.5.

\subsubsection{Residual Load Variance Objective}

The optimal solution for the residual load variance was obtained by using the respective operator. Figure 19 displays the predicted results for the next 30 years under each scenario. Figure 19a shows the results under scenario RCP2.6. The average residual load 
variance results for the five GCMs were 910, 916, and $867\left(10^{8} \mathrm{kWh}\right)$, for 2021-2030, 2031$2040,2041-2050$, respectively; while the uncertainty ranges were $(13.6 \%, 6.0 \%),(6.1,6.5 \%)$ and $(-9.7 \%, 17.5 \%)$. Figure $19 b, c$ show the results under scenarios RCP4.5 and RCP8.5, respectively, with relatively larger uncertainty ranges. Similar to the characteristics of power generation in the preceding section, the average residual load variance in RCP2.6 was larger than RCP8.5 at each interval, and larger than RCP4.5 for the first 20 years, but smaller following decade.

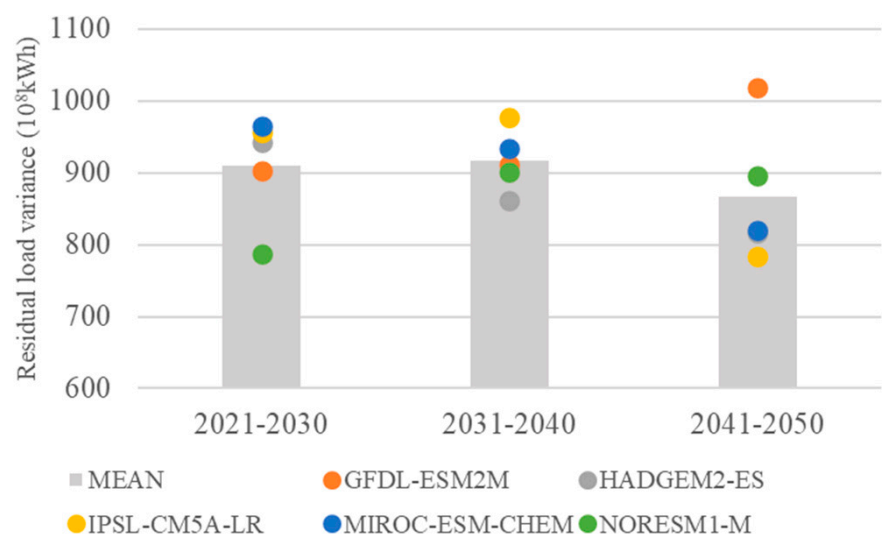

(a)

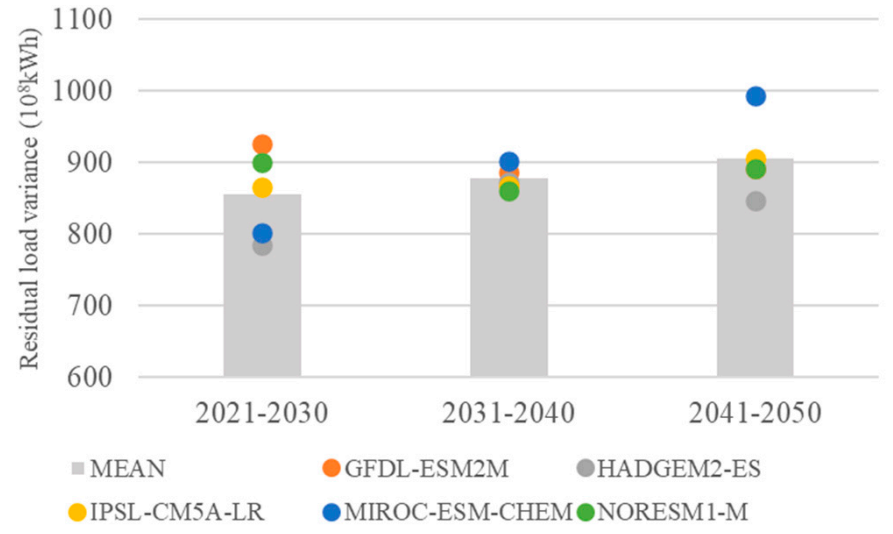

(b)

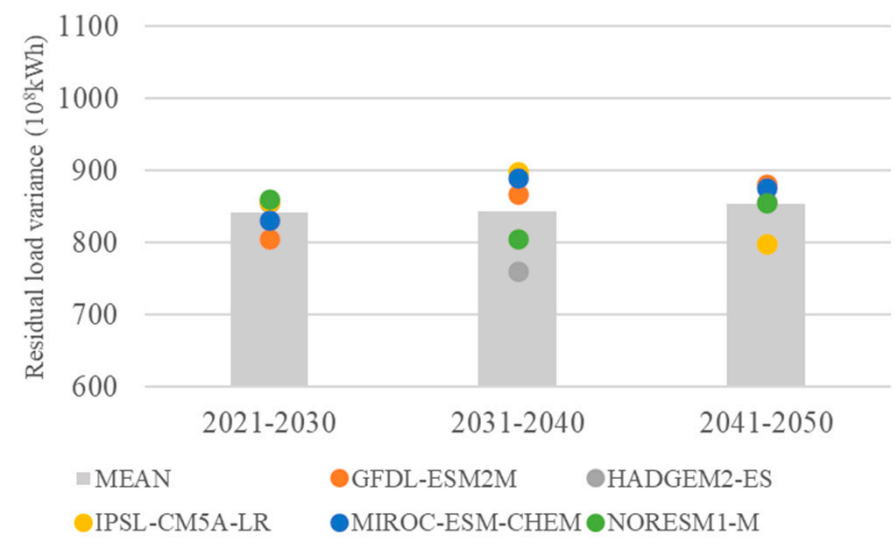

(c)

Figure 19. Residual load variance for the next three decades under scenarios: (a) RCP2.6, (b) RCP4.5, and (c) RCP8.5. 


\subsubsection{Combination of the Two Objectives}

The impact of climate change on the combination of the two objectives was evaluated using the contradiction between the two goals (Equation (29)):

$$
C=\frac{f_{2}^{i, \max }-f_{2}^{i, \min }}{f_{2}^{\max }-f_{2}^{\min }} \cdot\left(\frac{f_{1}^{i, \max }-f_{1}^{i, \text { min }}}{f_{1}^{\max }-f_{1}^{\min }}\right)^{-1}
$$

where $C$ is the variation ratio; $f_{1}^{\max }$ and $f_{1}^{\min }$ are the maximum and minimum values of the power generation objective in the solution set, respectively; $f_{2}^{\max }$ and $f_{2}^{\min }$ are the maximum and minimum values of the residual load variance objective in the solution set, respectively; $f_{1}^{i, \max (\min )}$ is the maximum (minimum) value of the solution $i$. When $C$ was larger, the reduced power generation due to the increase in the residual load variance was larger, implying a clear contradiction between the two goals; however, when $C$ was smaller, the reduced power generation due to the increase in the residual load variance was decreased, implying a more subtle contradiction between the two objectives.

Figure 20 shows the predicted variation ratios of the total power generation and residual load variance over the next 30 years, at decadal intervals. The results indicated that: under scenario RCP2.6 scenario indicated the average ratio of change between 2021-2030 and 2041-2050 was similar; under scenario RCP4.5, the average variation ratio in 2021-2030 was significantly higher than that in 2031-2040 or 2041-2050; however, the variation ratios in 2031-2040 and 2041-2050 were similar to those under RCP2.6; and the average variation ratio under the RCP8.5 scenario was even higher than that of RCP2.6.

In this section, we focus on the impact of climate change on two objectives: total power generation and residual load variance. The key factor associated with climate change and hydropower generation is streamflow, which is the same with the research done by Zhang [32] and Zhai [31]. However, due to the different climate scenarios selected, there is a difference in the predicted results. Zhang used a climate scenario with reduced rainfall and increased evaporation and concluded that agricultural profits are declining. Zhai adopted a climate scenario with increased discharge and concluded that extreme hydrological events are increasing. Trend of the objectives that are greatly affected by streamflow is generally depended on the trend of streamflow. This is also reflected in our article.

As can be seen in this paper, the results of RCP2.6 were more positive than those of RCP8.5. This is the same with the research done by Nam [20]. Nam carried out the assessment of vulnerable seasons for paddy irrigation under two climate change scenarios: RCP4.5 and RCP8.5. Results show that the total duration of the vulnerable irrigation seasons is longer in RCP8.5 than that in RCP4.5. Therefore, it is necessary to reduce carbon emissions to mitigate the adverse effects of climate change.

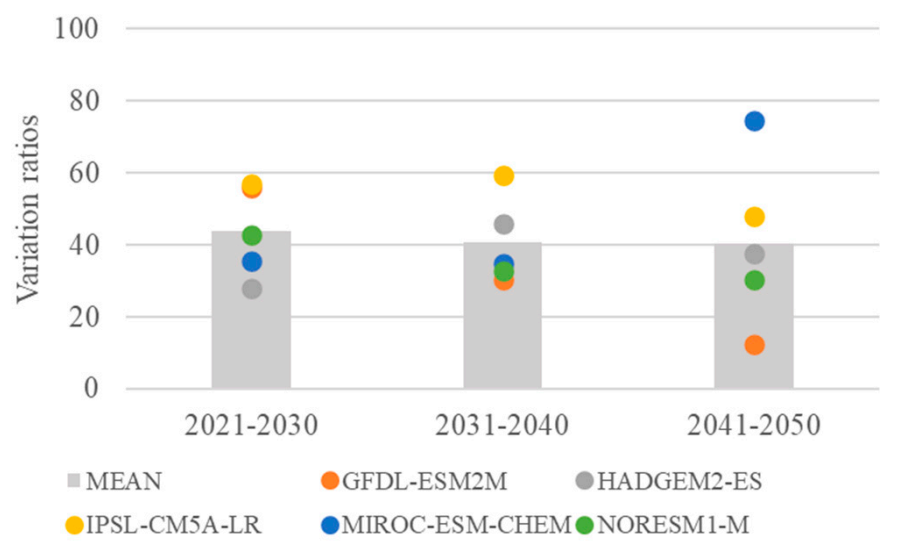

(a)

Figure 20. Cont. 


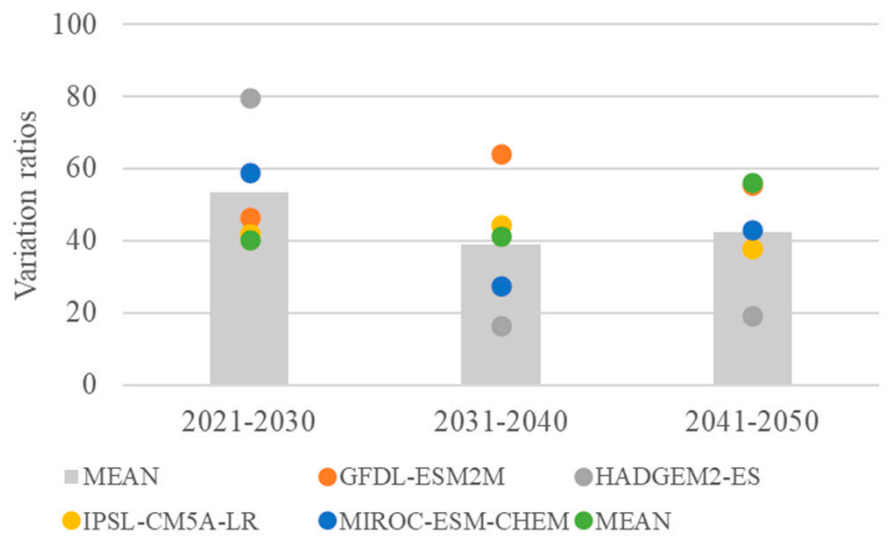

(b)

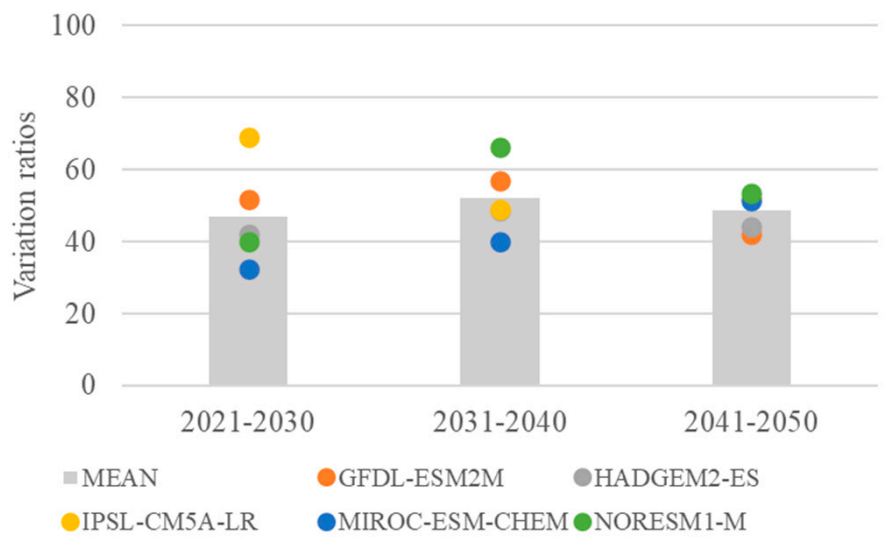

(c)

Figure 20. Predicted, decadal variation ratios under different climate scenarios: (a) RCP2.6, (b) RCP4.5, and (c) RCP8.5.

\section{Conclusions}

In the present research, a method to estimate the impact of climate change on hydropower was discussed, and a comprehensive impact of climate change assessment was made on the power generation of cascade hydropower stations in the lower reaches of the Jinsha River and residual load variance of the power grid. Climate change is affecting the amount of available water for power generation in a variety of ways, thereby altering the cascade of hydropower stations. The most common method to estimate the impacts of climate change on hydropower generation is to run a hydrological model under climate change conditions, obtain the changes in streamflow, and then assess the correlated impact on hydropower. An improved multi-objective cuckoo search algorithm has been proposed, and a variety of strategies for the optimal dispatch of hydropower stations, such as the gradient search strategy, single-entry external archive, and self-turning divergent operator strategy, were adopted to improve the efficiency of the algorithm.

In the case studies, the improved and unimproved algorithms were compared. The optimal results of the three typical years obtained by MoCS and GMoCS showed that the Pareto optimal frontier obtained by GMoCS was vastly superior to the results obtained by MoCS. The results also showed that the trends of total power generation of cascade hydropower stations and residual load variance of power grid were inversely correlated. After simulating the average variation ratios of five climate models under the three climate change scenarios, it was revealed that the strength of this relationship under the RCP 2.6 scenario was weaker than that under the RCP 8.5.

Overall, the impact of climate change on hydropower is reflected in the total power generation, as well as other indicators, including residual load variance. Although the results obtained through different climate models did not produce a unified conclusion, 
the results of RCP2.6 were more positive than those of RCP8.5, indicating that reducing carbon emissions is not only beneficial to ecological sustainability, but also has a positive impact on hydropower generation. Our approaches are also applicable for cascade reservoirs in other river catchments worldwide to estimate impact of climate change on hydropower development.

Author Contributions: Y.F. and C.W. conceived and designed the study; Y.F. and C.W. proposed the MoCS algorithm and the multi-objective hydropower generation model; Z.Y. and Y.W. wrote the predict model and performed the simulations. J.X. and Y.H. advised on the work and performed the final checks; All authors have read and agreed to the published version of the manuscript.

Funding: This work was supported by the National Natural Science Foundation of China (No. U2040212, No. 52009005) and the National Public Research Institutes for Basic R and D Operating Expenses Special Project (no. CKSF2019212/SZ).

Data Availability Statement: Not applicable.

Acknowledgments: We acknowledge the entire development team, whose help throughout this research was indispensable.

Conflicts of Interest: The authors declare no conflict of interest.

\section{References}

1. Mendes, C.A.B.; Beluco, A.; Canales, F.A. Some important uncertainties related to climate change in projections for the Brazilian hydropower expansion in the Amazon. Energy 2017, 141, 123-138. [CrossRef]

2. Fan, J.-L.; Hu, J.-W.; Zhang, X.; Kong, L.-S.; Li, F.; Mi, Z. Impacts of climate change on hydropower generation in China. Math. Comput. Simul. 2020, 167, 4-18. [CrossRef]

3. Gaudard, L.; Romerio, F.; Valle, F.; Gorret, R.; Maran, S.; Ravazzani, G.; Stoffel, M.; Volonterio, M. Climate change impacts on hydropower in the Swiss and Italian Alps. Sci. Total Environ. 2013, 493. [CrossRef]

4. Chang, J.; Wang, X.; Li, Y.; Wang, Y.; Zhang, H. Hydropower plant operation rules optimization response to climate change. Energy 2018, 160, 886-897. [CrossRef]

5. Zhong, W.; Guo, J.; Chen, L.; Zhou, J.; Zhang, J.; Wang, D. Future hydropower generation prediction of large-scale reservoirs in the upper Yangtze River basin under climate change. J. Hydrol. 2020, 588, 125013. [CrossRef]

6. Qin, P.; Xu, H.; Liu, M.; Du, L.; Xiao, C.; Liu, L.; Tarroja, B. Climate change impacts on Three Gorges Reservoir impoundment and hydropower generation. J. Hydrol. 2020, 580, 123922. [CrossRef]

7. Kim, K.; Jeong, H.; Ha, S.; Bang, S.; Bae, D.-H.; Kim, H. Investment timing decisions in hydropower adaptation projects using climate scenarios: A case study of South Korea. J. Clean. Prod. 2017, 142, 1827-1836. [CrossRef]

8. Boehlert, B.; Strzepek, K.M.; Gebretsadik, Y.; Swanson, R.; McCluskey, A.; Neumann, J.E.; McFarland, J.; Martinich, J. Climate change impacts and greenhouse gas mitigation effects on U.S. hydropower generation. Appl. Energy 2016, 183, 1511-1519. [CrossRef]

9. Huang, S.; Krysanova, V.; Hattermann, F. Projections of climate change impacts on floods and droughts in Germany using an ensemble of climate change scenarios. Reg. Environ. Chang. 2014, 15. [CrossRef]

10. Mezosi, G.; Bata, T.; Meyer, B.; Blanka, V.; Ladányi, Z. Climate Change Impacts on Environmental Hazards on the Great Hungarian Plain, Carpathian Basin. Int. J. Disaster Risk Sci. 2014, 5, 136-146. [CrossRef]

11. Hasan, M.M.; Wyseure, G. Impact of climate change on hydropower generation in Rio Jubones Basin, Ecuador. Water Sci. Eng. 2018, 11, 157-166. [CrossRef]

12. Falchetta, G.; Gernaat, D.E.H.J.; Hunt, J.; Sterl, S. Hydropower dependency and climate change in sub-Saharan Africa: A nexus framework and evidence-based review. J. Clean. Prod. 2019, 231, 1399-1417. [CrossRef]

13. Lu, S.; Dai, W.; Tang, Y.; Guo, M. A review of the impact of hydropower reservoirs on global climate change. Sci. Total Environ. 2020, 711, 134996. [CrossRef]

14. IPCC; McDowell, G.; Barr, I. 'High Mountain Areas' Chapter-IPCC Special Report on the Oceans and Cryosphere in a Changing Climate (SROCC); IPCC: Geneva, Switzerland, 2019.

15. Mishra, S.K.; Hayse, J.; Veselka, T.; Yan, E.; Kayastha, R.B.; LaGory, K.; McDonald, K.; Steiner, N. An integrated assessment approach for estimating the economic impacts of climate change on River systems: An application to hydropower and fisheries in a Himalayan River, Trishuli. Environ. Sci. Policy 2018, 87, 102-111. [CrossRef]

16. Feldbauer, J.; Kneis, D.; Hegewald, T.; Berendonk, T.U.; Petzoldt, T. Managing climate change in drinking water reservoirs: Potentials and limitations of dynamic withdrawal strategies. Environ. Sci. Eur. 2020, 32, 48. [CrossRef]

17. Helfer, F; Lemckert, C.; Zhang, H. Impacts of climate change on temperature and evaporation from a large reservoir in Australia. J. Hydrol. 2012, 475, 365-378. [CrossRef] 
18. Shu, J.; Qu, J.; Motha, R.; Xu, J.; Dong, D. Impacts of climate change on hydropower development and sustainability: A review. IOP Conf. Ser. Earth Environ. Sci. 2018, 163, 012126. [CrossRef]

19. Turner, S.W.D.; Hejazi, M.; Kim, S.H.; Clarke, L.; Edmonds, J. Climate impacts on hydropower and consequences for global electricity supply investment needs. Energy 2017, 141, 2081-2090. [CrossRef]

20. Nam, W.-H.; Kim, T.; Hong, E.-M.; Choi, J.-Y. Regional Climate Change Impacts on Irrigation Vulnerable Season Shifts in Agricultural Water Availability for South Korea. Water 2017, 9, 735. [CrossRef]

21. Carvajal, P.E.; Li, F.G.N.; Soria, R.; Cronin, J.; Anandarajah, G.; Mulugetta, Y. Large hydropower, decarbonisation and climate change uncertainty: Modelling power sector pathways for Ecuador. Energy Strategy Rev. 2019, 23, 86-99. [CrossRef]

22. Chilkoti, V.; Bolisetti, T.; Balachandar, R. Climate change impact assessment on hydropower generation using multi-model climate ensemble. Renew. Energy 2017, 109, 510-517. [CrossRef]

23. Sample, J.E.; Duncan, N.; Ferguson, M.; Cooksley, S. Scotland's hydropower: Current capacity, future potential and the possible impacts of climate change. Renew. Sustain. Energy Rev. 2015, 52, 111-122. [CrossRef]

24. Pereira-Cardenal, S.; Madsen, H.; Arnbjerg-Nielsen, K.; Riegels, N.; Jensen, R.; Mo, B.; Wangensteen, I.; Bauer-Gottwein, P. Assessing climate change impacts on the Iberian power system using a coupled water-power model. Clim. Chang. 2014, 126, 351-364. [CrossRef]

25. González-Villela, R.; Martínez, M.J.M.; Sepúlveda, J.S.S. Effects of climate change on the environmental flows in the Conchos River (Chihuahua, Mexico). Ecohydrol. Hydrobiol. 2018, 18, 431-440. [CrossRef]

26. Givati, A.; Thirel, G.; Rosenfeld, D.; Paz, D. Climate change impacts on streamflow at the upper Jordan River based on an ensemble of regional climate models. J. Hydrol. Reg. Stud. 2019, 21, 92-109. [CrossRef]

27. Clifton, C.F.; Day, K.T.; Luce, C.H.; Grant, G.E.; Safeeq, M.; Halofsky, J.E.; Staab, B.P. Effects of climate change on hydrology and water resources in the Blue Mountains, Oregon, USA. Clim. Serv. 2018, 10, 9-19. [CrossRef]

28. Bhatta, B.; Shrestha, S.; Shrestha, P.K.; Talchabhadel, R. Evaluation and application of a SWAT model to assess the climate change impact on the hydrology of the Himalayan River Basin. CATENA 2019, 181, 104082. [CrossRef]

29. de Queiroz, A.R.; Faria, V.A.D.; Lima, L.M.M.; Lima, J.W.M. Hydropower revenues under the threat of climate change in Brazil. Renew. Energy 2019, 133, 873-882. [CrossRef]

30. Arango-Aramburo, S.; Turner, S.W.D.; Daenzer, K.; Ríos-Ocampo, J.P.; Hejazi, M.I.; Kober, T.; Álvarez-Espinosa, A.C.; RomeroOtalora, G.D.; van der Zwaan, B. Climate impacts on hydropower in Colombia: A multi-model assessment of power sector adaptation pathways. Energy Policy 2019, 128, 179-188. [CrossRef]

31. Zhai, M.Y.; Lin, Q.G.; Huang, G.H.; Zhu, L.; An, K.; Li, G.C.; Huang, Y.F. Adaptation of Cascade Hydropower Station Scheduling on A Headwater Stream of the Yangtze River under Changing Climate Conditions. Water 2017, 9, 293. [CrossRef]

32. Zhang, W.; Liu, P.; Wang, H.; Lei, X.; Feng, M. Operating rules of irrigation reservoir under climate change and its application for the Dongwushi Reservoir in China. J. Hydro-Environ. Res. 2017, 16, 34-44. [CrossRef]

33. Yang, X.S.; Deb, S. Cuckoo Search via Levy Flights. Mathematics 2010, 210-214.

34. Geressu, R.; Harou, J. Reservoir system expansion scheduling under conflicting interests. Environ. Model. Softw. 2019, 118, 201-210. [CrossRef]

35. Feng, Y.; Zhou, J.; Mo, L.; Wang, C.; Yuan, Z.; Wu, J. A Gradient-Based Cuckoo Search Algorithm for a Reservoir-Generation Scheduling Problem. Algorithms 2018, 11, 36. [CrossRef]

36. Warszawski, L.; Frieler, K.; Huber, V.; Piontek, F.; Serdeczny, O.; Schewe, J. The Inter-Sectoral Impact Model Intercomparison Project (ISI-MIP): Project framework. Proc. Natl. Acad. Sci. USA 2014, 111, 3228-3232. [CrossRef]

37. Hempel, S.; Frieler, K.; Warszawski, L.; Schewe, J.; Piontek, F. A trend-preserving bias correction-The ISI-MIP approach. Earth Syst. Dyn. 2013, 4, 219-236. [CrossRef]

38. Berti, A.; Tardivo, G.; Chiaudani, A.; Rech, F.; Borin, M. Assessing reference evapotranspiration by the Hargreaves method in north-eastern Italy. Agric. Water Manag. 2014, 140, 20-25. [CrossRef]

39. Feng, Y.; Zhou, J.; Mo, L.; Yuan, Z.; Zhang, P.; Jiang, W.; Wang, C.; Wang, Y. Long-Term Hydropower Generation of Cascade Reservoirs under Future Climate Changes in Jinsha River in Southwest China. Water 2018, 10, 235. [CrossRef] 